W34m

No. S-69-23

Cop. 3

MISCELLANEOUS PAPER S-69-23

\title{
PRECOMPRESSION FOR IMPROVING FOUNDATION SOILS \\ by
}

S. J. Johnson

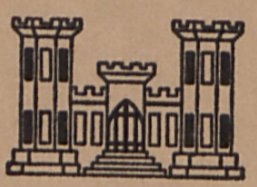

June 1969

Pubilishied by

U. S. Army Engineer Waterways Experiment Station CORPS OF ENGINEERS

Vicksburg, Mississippi

THIS DOCUMENT HAS BEEN APPROVED FOR PUBLIC RELEASE AND SALE; ITS DISTRIBUTION IS UNLIMITED 


\title{
PRECOMPRESSION FOR IMPROVING FOUNDATION SOILS
}

\author{
by
}

S. J. Johnson

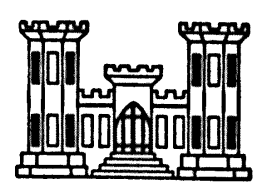

June 1969

Published by

U. S. Army Engineer Waterways Experiment Station CORPS OF ENGINEERS

Vicksburg, Mississippi

ARMY.MRC VICKEBURG. MISS.

THIS DOCUMENT HAS BEEN APPROVED FOR PUBLIC RELEASE AND SALE; ITS DISTRIBUTION IS UNLIMITED 
Foreword

This state-of-the-art paper was presented by $\mathrm{Mr}$. S. J. Johnson at the American Society of Civil Engineers Specialty Conference on Placement and Improvement of Soils to Support Structures, which was held at the Massachusetts Institute of Technology in August 1968, and will be published in the Proceedings of the Conference. The paper was cleared for presentation and publication by the Office, Chief of Engineers (ENGTL).

Mr. Johnson is Special Assistant in the Soils Division, U. S. Army Engineer Waterways Experiment Station (WES).

The Director of.WES during the preparation of this paper was COI Levi A. Brown. Technical Directors were Messrs. J. B. Tiffany and F. R. Brown. 
PRECOMPRESSION FOR IMPROVING FOUNDATION SOILS

By Stanley J. Johnson, ${ }^{1}$ F. ASCE

\section{INTRODUCTION}

In the 16 years that have elapsed since the first conference on soil stabilization at the Massachusetts Institute of Technology, significant changes have occurred in subsoil stabilization procedures that have made it possible to construct buildings, highway embankments, earth dams, and a wide variety of tanks and structures at reduced cost in many areas of poor subsoils. In 1952, precompression techniques for improving weak and compressible soils sufficiently to support structures hảd been used but were not well known, were not always successful, and had not always been carefully thought out. At the 1952 conference, interest was centered primarily about the concept of precompression and not about details involved. Since then, the concept has been more widely accepted and principal interest is proper application of the concept and in details that affect final results. The rapidly increasing interest in precompression techniques is due to the large savings that often result and to the increasing scarcity of advantageously located land that is available and that offers good foundation conditions. Large areas of poor subsoils, including many that are partially or totally submerged, are found in or near many of the major cities of the world. These marginal areas can be reclaimed at a small fraction of the cost of other alternatives, and precompression is often applicable for this purpose.

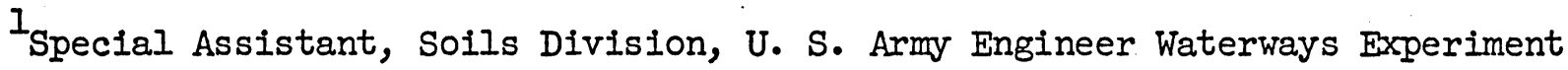
Station, Vicksburg, Miss. 
Densification or improvement of soils through use of preloading techniques is discussed from the viewpoint of a practicing engineer considering preloading techniques to improve foundation subsoils which, in their natural conditions, are unsuitable for supporting a structure. The procedures discussed are based on current application of appropriate practical and theoretical knowledge, and significant improvements or modifications can be expected from research in. progress. While settlements resulting from secondary compression are not generally evaluated in foundation engineering, it is necessary to do so with the precompression technique. Because preloading is generally designed to avoid settlement of permanent structures resulting from primary consolidation, postconstruction settlements from secondary compression start immediately and may be significant during the life of structures. Postconstruction settlements resulting from secondary compression can be evaluated and reduced where necessary. While the procedures for doing this are approximate and in a stage of development, they are considered suitable for design purposes where properly and conservatively applied.

. Whereas it may be desirable from a research viewpoint to regard primary consolidation and secondary compression as parts of a continuous physical phenomenon, It is more convenient from a practical standpoint to consider these phases separately. For design purposes, it is satisfactory to accept the physical phenomenon of secondary compression, leaving explanations of its basic cause for further research. 
Many terms have been used to describe preconsolidation or precompression techniques, including such terms as preloading, surcharge loading, and overloading. The following definitions ${ }^{1,2}$ are used herein:

Precompression

or

Preconsolidation

Preloadịng

Surcharging

Primary Consolidation

Secondary Compression
Compressing the soil under an applied pressure prior to placing or completing the structure load

A means for accomplishing precompression, usually by earth fill, water load in tanks, etc.

Preloading in excess of final loading

Terzaghi concept

A volume change which continues after completion of primary consolidation. It is characterized by a straight-line relation between volume change and logarithm of time.

(Secondary compression may represent a plastic readjustment of stress between soil grains, and appears related to existence of shear stresses.) 


\section{Historical}

The use of precompression techniques became popular in the early 1940s in connection with use of sand drains for highway construction, ${ }^{2}$ and probably stimulated the use of preloading without sand drains. From an uncertain beginning, precompression of compressible foundations for structures gradually came into more extensive use. Perhaps the first application of preloading at a major hydraulic structure was made by the Corps of Engineers in 1949 at the Morganza Floodway Control Structure ${ }^{3}$ to eliminate about 2-1/2 ft of settlement that would otherwise have occurred beneath abutment fills. Since then, the Corps has successfully used preloading at several other major hydraulic structures, that is, the Overbank and Low Sill Control Structures at the Old River Project; ${ }^{4,5}$ Porter $^{2}$ used preloading at abutments and piers of a highway bridge in the Jersey Meadows for the New Jersey Highway Department; and Wilson, ${ }^{6}$ in 1953, described examples of preload fills to control settlement of structures. At the time of the 1952 Soil Stabilization Conference at MIT, few examples were available to illustrate use of precompression techniques for structures, although preload fills were becoming common for highways, even though a number were unsuccessful. However, by 1964 when the ASCE Conference on Design of Foundations for Control of Settlements was held at Northwestern University, many applications had been made of various precompression techniques for a variety of structures; a number of these are described in the Proceedings of that conference. Some types of structures for which precompression has been used are listed in Table 1.

. Rapidly increasing urban development is making utilization of many marginal areas economically attractive, including areas of poor subsoils that are partially or totally submerged. Also, modern high-speed roadways cannot avoid 
TABLE 1.-TYPES OF STRUCTURES FOR WHICH PRECOMPRESSION HAS BEEN USED

Earth Abutments of Hydraulic Structures:

Morganza Floodway

Old River Low Sill Control Structure

Old River Overbank Control Structure

One-story Warehouses

One-story Manufacturing Buildings

Five-story Hospital

Three-story Dormitories

Four-story Office Building

Churches and a Cathedral
Reinforced Concrete Buildings

Bowling Alley

Shopping Centers

Boiler House

Marginal Wharves

Piers

POI Storage Tanks

Highway Embankments

Bridge Piers and Abutments

Airfield Runways 
some areas having poor subsoils, and swamps are often the only areas available for new roads at a reasonable cost for land acquisition. Precompression and other alternatives to pile-supported construction often make possible utilization of areas of poor subsoils without compromising satisfactory postconstruc-. tion behavior of embankments or structures. Nevertheless, the method is not always applicable.

Most precompression applications involve weak and highly compressible soils. While such materials are often greatly improved by preloading, they still may be capable of supporting only relatively light loads and heavy concentrated loadings cannot generally be used. However, where subsoils are somewhat borderline but not too weak and compressible, preloading has been used to reduce settlements beneath low multistory buildings. Types of Soil Improved by Preloading

Almost every conceivable type of soil has been improved by the precompression technique. These include organic and inorganic silts and clays, peaty soils, peats, cinders, rubbish and miscellaneous fills, and sanitary land fills. (Construction over sanitary land fills should be approached with extreme caution, as pointed out by Sowers. ${ }^{7}$ ) Materials that have been successfully preloaded have had water contents from 20 to 1000 percent or more, Atterberg limits that plot both above and below the A-Iine, and include both sensitive and insensitive soils. Whereas peats and peaty soils were formerly. con-sidered unsuitable for precompression applications and were excavated, there is an increasing tendency to leave them in place and to stabilize them by precompression. Many such soils consolidate rapidly and are often less troublesome than underlying soft clays, which are generally also present. Peaty soils usually consolidate so rapidly that means to accelerate drainage during consolidation, such as sand drains, are unnecessary unless loads are high. 
Factors Involved in Precompression

Factors involved when considering preloading are listed in Table 2. They basically relate to (1) owner and user considerations, (2) site and design considerations, and (3) evaluation.

Owner and User Considerations

When evaluating the feasibility of using preloading, potential consequences of unexpected behavior must be considered as regards amount and rate of settlement occurring both during the preloading period and after the structure has been constructed. That rate of settlement is a highly important factor when considering preloading is obvious; if it is miscalculated, a site may still be unsuitable at the time construction must begin.

The establishment of tolerable differential settlements, see Table 3, requires communication between the engineer, the owner, and the user. What might be tolerated under one condition becomes intolerable under other conditions, and it is necessary to determine differential settlements acceptable to all parties. Many studies have been made to determine the relationship between differential settlement and structural damage, and special designs have been prepared to accommodate large differential settlements. While total settlements affect surface drainage and utilities entering a structure, structural damage is caused almost entirely by differential settlements. Allowable values of differential settlements vary widely for different structures and between different authorities. This subject is too broad to discuss herein; some references $^{8-15}$ proposing design criteria are listed in. Table 3 . Site and Design Considerations

A significant requirement when considering precompression techniques is the need to make especially detailed subsoil investigations, laboratory tests, and design analyses, and to provide high quality field inspection. 
a. OWNER AND USER CONSIDERATIONS

Cost

Time available

Design loadings

Allowable postconstruction settlements (total and differential)

b. SITE AND DESIGN CONSTDERATIONS

Geological history

Previous loading history

Subsurface materials; nature and distribution

Consolidation characteristics

Strength properties

Availability of fill for surcharging

c. EVALUATION

Cost vs other alternatives

Safety factor

Consequences of unexpected behavior

Amount of settlement during preloading

Rate of settlement during preloading

Postconstruction settlements 
a. TOTAI SETTLEMENTS PRINCIPAILY AFFECT:

Drainage around structure

Utility connections

b. DIFFERENTIAL SETTLEMENTS AFFECT STRUCTURE

c. REFERENCES FOR TOLERABLE DIFFERENTIAL SETTLEMENTS:

Brickell and Smith, ${ }^{8}$ New Zealand, Eng., Oct. 1959

Polshin and Tokar, 9957 Iondon Conf., 4th ICSM\&FE

Feld, 101957 Iondon Conf., 4th ICSM\&FE

Sowers, 111957 Iondon Conf., 4th ICSM\&FE

Navy Design Manual, DM- $7^{12}$

Ohsaki, 13 Japanese Society SM\&FE, April 1960

McKinely, 14 JSM\&FD, ASCE, Sept. 1964

Feld, ${ }^{15}$ JSM\&FD, ASCE, May 1965 
Precompression is generally used where subsoils are weak and highly compressible. This introduces major questions concerning foundation stability under preloads and the need to predict relatively accurately both magnitude and time rate of consolidation. Precompression design is complex and requires a relatively high degree of competence and investment in time and money. However, since construction cost savings are often extremely large, additional design costs are of negligible importance, provided that the engineer and the owner recognize this. Hardly any activity of the soils and foundation engineer earns such a large return on invested effort. While an almost incredibly large number of distressing failures have plagued precompression applications, these resulted mainly from insufficient attention to the need for detailed investigation, design, and supervision.

The economic advantages of precompression often depend upon availability of economical means for applying required preloads. These means may include (1) earth fills, (2) water loading in tanks, ${ }^{16}$ (3) groundwater lowering ${ }^{17}$ possibly assisted by vacuum techniques, ${ }^{18}(4)$ anchors and jacks, ${ }^{19}$ and possibly (5) vacuum mats (as proposed by Kjellman ${ }^{20}$ at the $1952 \mathrm{MIT}$ conference). The latter concept has not yet been put into practice, although a recent magazine article suggests that it may be tried in Japan. Earth fills and water loading in tanks are the most common methods; the others are more specialized and of limited applicability. Water loading in storage tanks is often economical where tanks are to be water-tested and where products to be stored weigh less than water. Excessive settlements occurring during tank water loading can be corrected by mud jacking, generally at a modest cost. Groundwater lowering appears useful where a sand layer with a high groundwater level overlies the compressible soil, but is considered of limited benefit where the compressible stratum extends to the ground surface. 
Evaluation of Precompression

A decision to use precompression is influenced by economic, time, technical, and psychological factors. Where subsoil conditions are poor and loads are light to moderate and relatively uniform, economic factors generally favor precompression over other alternatives, such as deep foundations, excavation and backfill, or other subsoil treatments. This is especially true where loaded areas are large. However, the overall economics of a project may relegate construction economy to a minor role.

An important feature of precompression is the relatively long time, months up to a year or more, required for it to be beneficial. Considerable time and added costs are also entailed for subsoil investigation, testing, and design, although preliminary designs for feasibility purposes can readily be prepared from incomplete data. Advance planning that does not anticipate possible use of preloading and the time required for consolidation may prevent use of the precompression technique even though potential cost savings are large.

The importance of "attitude" depends upon the nature of the work, the likes and dislikes of those making decisions, the experience available in or to an organization, and the engineer-client relationship. Attitude differences between engineers are illustrated by the following. To some highway engineers, a well-designed precompression application results in a smoother riding surface than does a structure on piles, but öther engineers would use a structure even if it cost 50 percent more than a well-stabilized foundation and earth fill. Major differences in attitude regarding reliability of subsoil stabilization by precompression exist both regionally and locally. Provided design and construction supervision are competent (and often this has not been the case), it seems safe to evaluate precompression for its economy and feasibility for any given set of conditions without assuming that any significant uncertainties are attached to its use: 
INFLUENCE OF GEOLOGY AND SUBSOIL CHARACTERISTICS

General

The geological and previous loading history of a site and details regarding subsoil types, stratification, strength, and compressibility characteristics are of relatively greater importance for successful use of precompression techniques than they are for other alternatives. Without minimizing the importance of theoretical contributions, an excellent knowledge of subsoil properties at a site is generally more important than use of advanced theoretical concepts. Some practical aspects of design are, therefore, discussed in detail in subsequent paragraphs. Because magnitude and time rate of consolidation are involved, subsoil stratification must be determined in detail, and enough continuous samples must be obtained to locate even thin silt and sand layers and to determine their continuity.

Internal Drainage Layers

The significance of thin sand or silt layers within the compressible stratum is related to the size of structure proposed; such drainage layers may have several effects. If a small structure is considered for which a relatively narrow preloading fill or a small water loaded tank will be used (see Fig. la), even thin sand and silt layers may permit rapid consolidation and eliminate the need to consider means for accelerating consolidation. However, this benefit may be accompanied by abnormally high pore-water pressures in the sand or silt layers beyond the edge of the fill or water-filled tank, decreasing the shear resistance of the sand or silt layers to less than that of the surrounding weak material. Such pore-water pressures may have to be relieved by sand drains functioning as relief wells or by cased wells located at the toes of the fill or at the perimeter of a tank. 8,21 


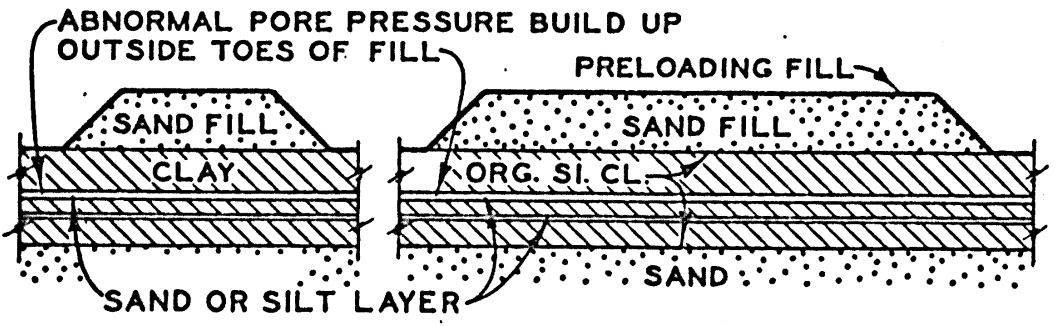

a. SHORT OR

NARROW STRUCTURE

2- OR 3-DIMENSIONAL

CONSOLIDATION b. LONG AND

WIDE STRUCTURE

VERT. CONSOLIDATION BENEATH CENTRAL PORTION;2-DIMENSIONAL NEAR EDGES

INFLUENCE OF

STRUCTURE SIZE RELATIVE TO

THICKNESS OF COMPRESSIBLE SOIL 
If a preloading fill covers a long and wide area. (see Fig. Ib), the effect of sand or silt layers may be insignificant in accelerating the time rate of consolidation beneath the central portion of the fill where consolidation may occur almost exclusively as a result of drainage in a vertical direction. However, high pore-water pressures may still develop beyond the edges.of the fill. As a result, sand drains or other pressure relief wells may be required beneath the central part of large preload fills and also beneath the exterior edges, even where the compressible stratum is stratified or varved. Local experience with rate of settlement of previously constructed structures--a most important thing to take advantage of-- must not be used without taking into account the size of loaded areas and the consequent effect on relative efficiencies of intermediate sand or silt layers. •

Drainage in Preload Fill and in Previous Substrata

Where wide preload fills are used, the groundwater level within the fill tends to rise, thereby decreasing the effectiveness of the preload. This effect may be especially severe with large fills; where fills are placed hydraulically, the groundwater level in the fill may extend to within a few feet of its surface upon completion of fill placement: The groundwater can be lowered and this effect eliminated by placing horizontal pipe or gravel drains within the fill. Where buildings or other structures are to be constructed over horizontal drains placed within the fill, the drains are often constructed of gravel with properly sized filters surrounding them to avoid possible loss of ground that would occur if metal collector pipes were used and broke because of differential settlements or deteriorated because of corrosion.

While the above effect is perhaps rather obvious, a less apparent development where wide fills are used may be increased pore-water pressures in pervious material beneath the compressible stratum. This will also slow down the rate 
of consolidation and may introduce stability problems at outer edges of the preload area, where the increased pore-water pressures may decrease effective stresses so much that shear resistance in the underlying sand becomes critical as regards stability. Both of the above conditions were experienced at Port Elizabeth and at Newark Airport in large-scale fill operations by the Port of New York Authority, as discussed by York 22 and elsewhere.

Under a large preload fill at Newark Airport, ${ }^{22}$ the pore-water pressure in a silty sand underlying about $10 \mathrm{ft}$ of peat and organic silt had increased about $25 \mathrm{ft}$ upon completion of fill operations and was within 4 ft of the pore-water pressure in the center of the compressible stratum. At the same time, the water level in the sand preload fill increased about $17 \mathrm{ft}$. While the increases in pore-water pressure in the fill and in the underlying silty sand were temporary, except for an 8-ft permanent rise in water level in the fill, such temporarily high pore-water pressures, if not anticipated, could cause stability problems at the edge of the fill (see Fig. 2). The buildup of high groundwater levels within the fill can be avoided by drainage, as was done in a large project at New Haven. ${ }^{23}$ In general, the design of large preload fills should assume the existence of a groundwater mound within the fill unless pipe or gravel drains are placed within $1 t$. While this effect is most pronounced with fills placed hydraulically, it also applies to those placed by normal earth moving operations. Consolidation Properties

While subsoil consolidation characteristics are determined by laboratory consolidation tests performed on undisturbed samples, even the best undisturbed samples are still disturbed to some extent. This is of practical importance because the quality of undisturbed samples significantly affects both the computed time rate of consolidation and the magnitude of settlement. While the effect of sample quality on void ratio-pressure curves is well known (see 


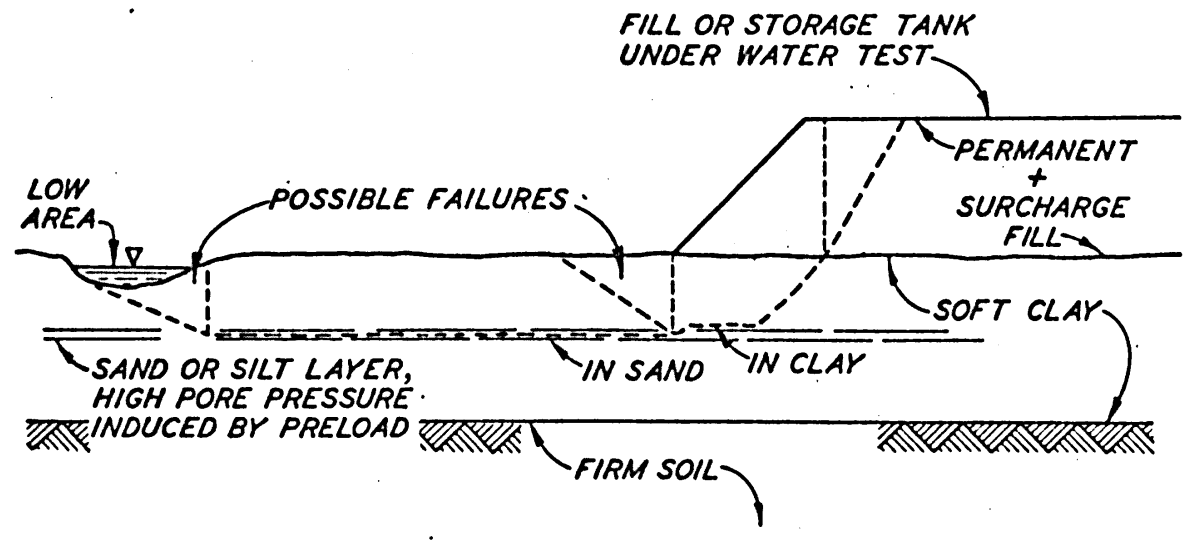

EFFECT OF PRELOAD - INDUCED PORE PRESSURE ON STABILITY 
Fig. 3), the significant effect of sample quality on the coefficient of consolidation is not as well recognized. Since the time required to achieve a given degree of consolidation is directly proportional to the coefficient of consolidation, the quality of undisturbed samples affects estimated results of precompression application and possible need for means to accelerate consolidation.

In general, the coefficient of consolidation $\left(c_{v}\right)$ of good undisturbed samples is relatively high for stresses less than the preconsolidation stress but decreases as the preconsolidation stress is approached and exceeded, and thereafter generally increases. However, if samples are moderately disturbed, the coefficient of consolidation is relatively low for stresses less than the prei, consolidation stress but increases with increasing stress and, for stresses exceeding the preconsolidation stress, may approach values for good undisturbed samples, as shown in Fig. 3. However, for disturbance approaching complete remolding, it may be substantially lower than for good undisturbed samples even at high stresses. The coefficient of compressibility $a_{v}$ is not so drastically affected by moderate disturbances as the coefficient of consolidation, but nevertheless it also reflects sample quality. While the coefficient of consolidation varies greatly with stress, the Terzaghi theory assumes it to be constant; although the variability of the factors composing it, $c_{v}=\frac{k\left(l+e_{0}\right)}{a_{v} r_{W}}$, has always been recognized. It is obviously important to use design values of the coefficient of consolidation that are compatible with maximum effective stresses to be imposed by preloading. This factor is frequently overlooked, even by experienced engineers, with a tendency to use the higher values of the coefficient of consolidation that correspond to initial or somewhat higher stresses. Where $c_{v}$ is computed using the $k$ value from results of field permeability tests, the value of $\ddot{k}$ should be that for vertical flow. where sand drains are not used and should be adjusted to reflect the decrease that occurs with consolidation. 


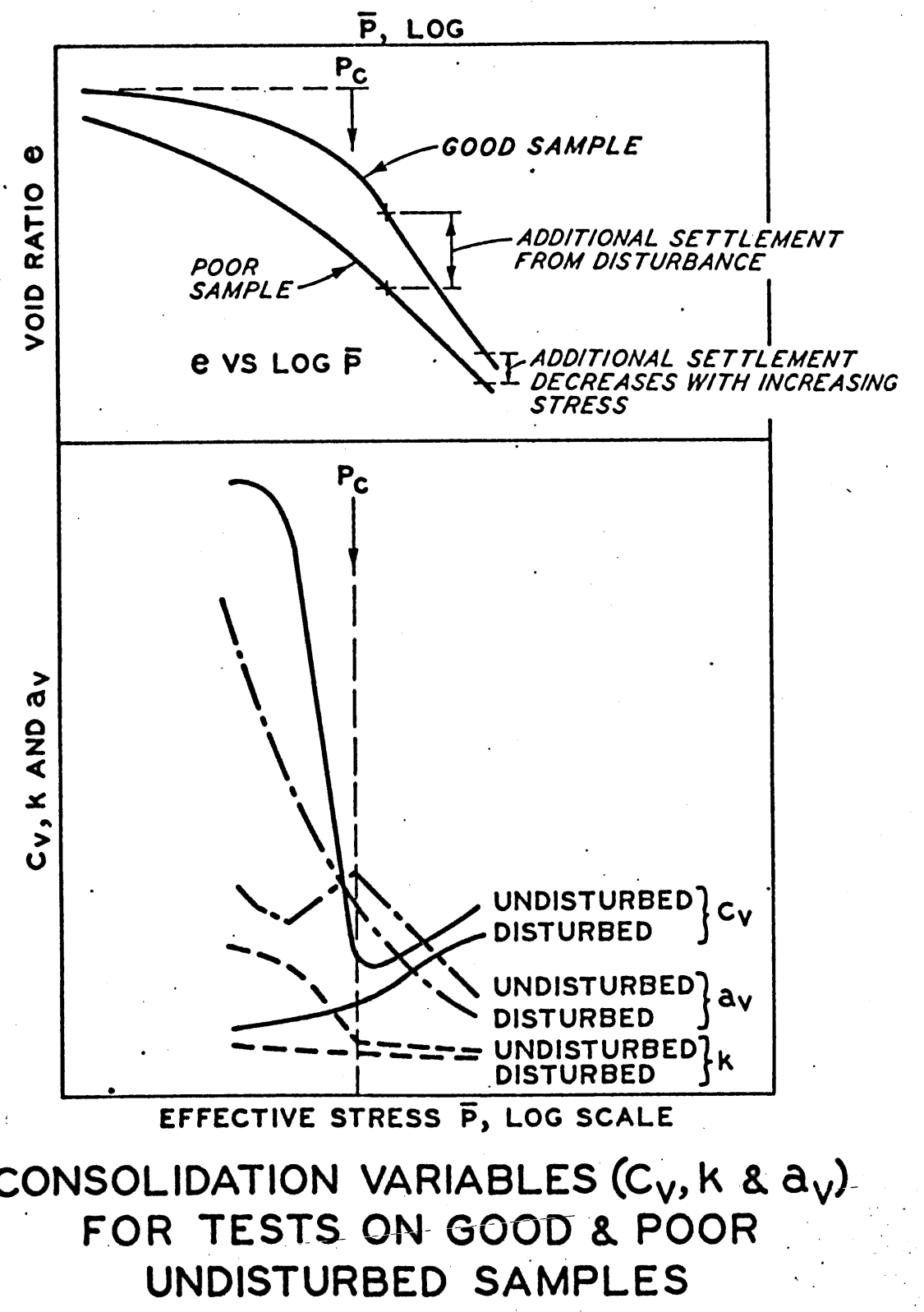

Fig. 3 
Some additional features of laboratory consolidation tests on poor samples are shown on Fig. 4, which depicts test results for a poor undisturbed sample. The coefficient of consolidation does not exhibit high values for low stresses, as for tests on good samples; also, the time curves for individual load increments undergo increasing compression in a relatively uniform manner. This can be compared with time curves for a good undisturbed sample (see Fig. 5), which, in the vicinity of the preconsolidation stress, undergo an abrupt increase in compression. It is often possible to use this characteristic as an aid in evaluating sample quality. By comparing Figs. 4 and 5 for tests on poor and good samples, respectively, it is evident that not only is the coefficient of consolidation affected by sample quality but that the coefficient of secondary compression is similarly affected. For stresses less than the preconsolidation stress, the coefficient of secondary compression is generally quite low; it . increases as the preconsolidation stress is approached and for higher stresses may ultimately remain about constant or may decrease somewhat.

Secondary Compression

The coefficient of secondary compression $c_{\alpha}$ is equal to the vertical strain per $\log$ cycle of time. Plots of $c_{\alpha}$ versus effective stress to a log scale (see Fig. 6) illustrate how. $c_{\alpha}$ increases as the preconsolidation stress is approached and exceeded but then becomes essentially constant or decreases slightly. While $c_{\alpha}$ is generally determined from laboratory consolidation-tests In which each loading increment is double the previous one, there is some indication that smaller increments cause somewhat larger values of $c_{\alpha}$.

When simulating field loading conditions in which preloading is expected to minimize postconstruction settlements resulting from secondary compression, it Is desirable to investigate the effect of stress decrease on the coefficient of secondary compression. Iimited tests ${ }^{2}$ indicate that two effects are associated 

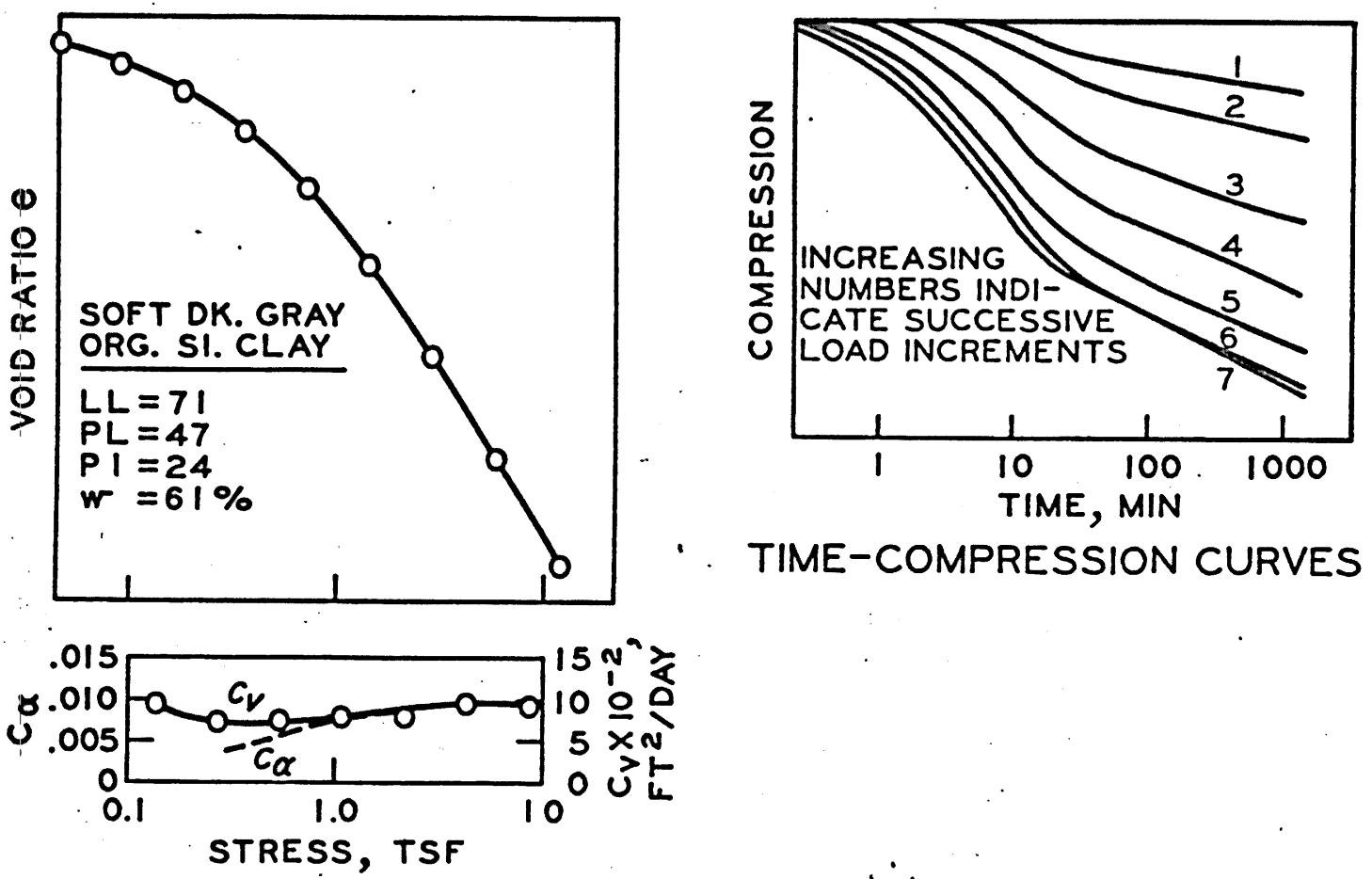

TIME-COMPRESSION CURVES

LABORATORY CONSOLIDATION CURVES "POOR" UNDISTURBED SAMPLES 

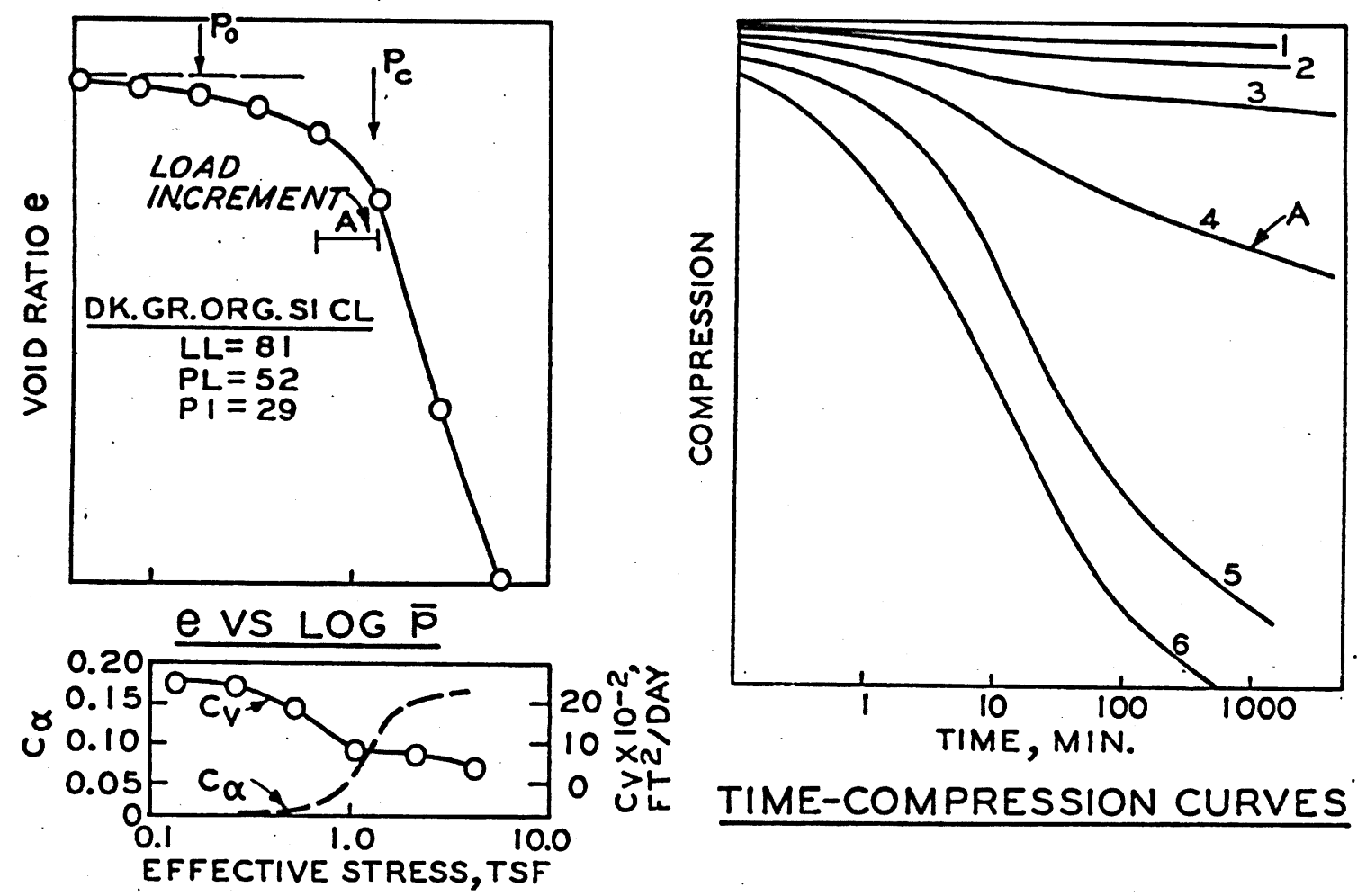

LABORATORY CONSOLIDATION CURVES

"GOOD"UNDISTURBED SAMPLE 


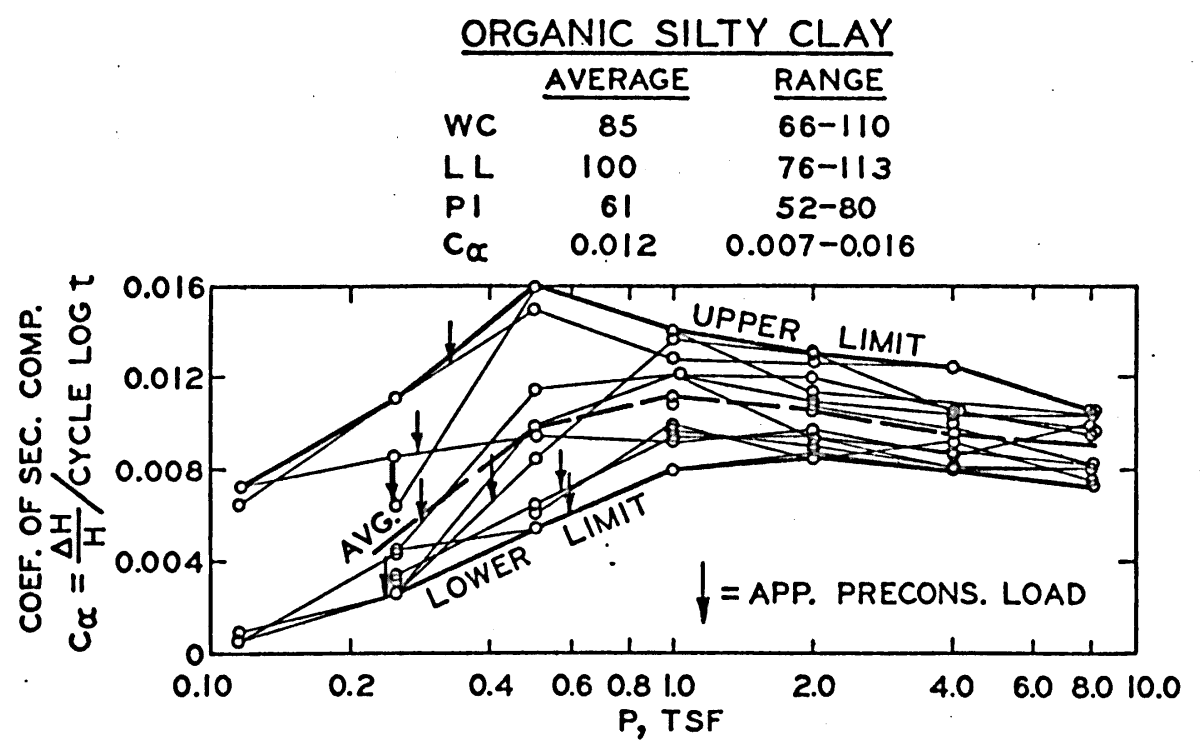

COEFFICIENT OF SECONDARY COMPRESSION $C_{\propto}$ (AFTER JONAS) VS EFFECTIVE STRESS, ONE-DIMENSIONAL CONSOLIDATION 
with temporary preloading, as indicated schematically in Fig. 7. This figure illustrates primary and secondary compression for a sample not subjected to surcharge loading and settlement following removal of simulated surcharge loads of different intensities. For a period of time after unioading, little or no secondary compression is evident, and there may be slight swelling (which is not indicated in Fig. 7) but thereafter secondary compression appears, but at a reduced rate as compared to a test which is not unloaded. As the magnitude of simulated surcharge stress increases, the time interval following removal of the surcharge load during which little secondary compression occurs also increases, and when secondary compression reappears, the coefficient of secondary compression $c_{\alpha}$ decreases. The variation of $c_{\alpha}$ during loading and unloading ${ }^{2}$ (see Fig. 8), illustrates that stress decrease from removal of temporary surcharge loading materially decreases the coefficient of secondary compression. This is also illustrated by Fig. 9 on which values have been plotted derived from field observations made in New Jersey by the New Jersey Highway Department ${ }^{2}$ and laboratory values reported by Moran, et al ${ }^{2}$ and. by Simons. ${ }^{25}$

Laboratory tests to investigate the effect of stress decrease reported by Simons $^{25}$ (see Fig. 10) also illustrate the benefits of surcharging; however, these tests were only carried to 10,000 minutes, as compared to the four to six weeks required in the tests illustrated schematically in Fig. 7. Nevertheless, the tests by Simons also illustrate that surcharge loading effectively reduces settlements resulting from secondary compression. Similar data, reported by Kapp, et al ${ }^{26}$ and shown in Fig. 11, also demonstrate, on a laboratory scale, the benefits of surcharge loading in reducing secondary compression. Here again, however, the loading time after removal of surcharge load was insufficient to determine if and how secondary compression settlements would have reappeared (see Case A, Fig. 11). Tests of the type illustrated in Figs. 7, 


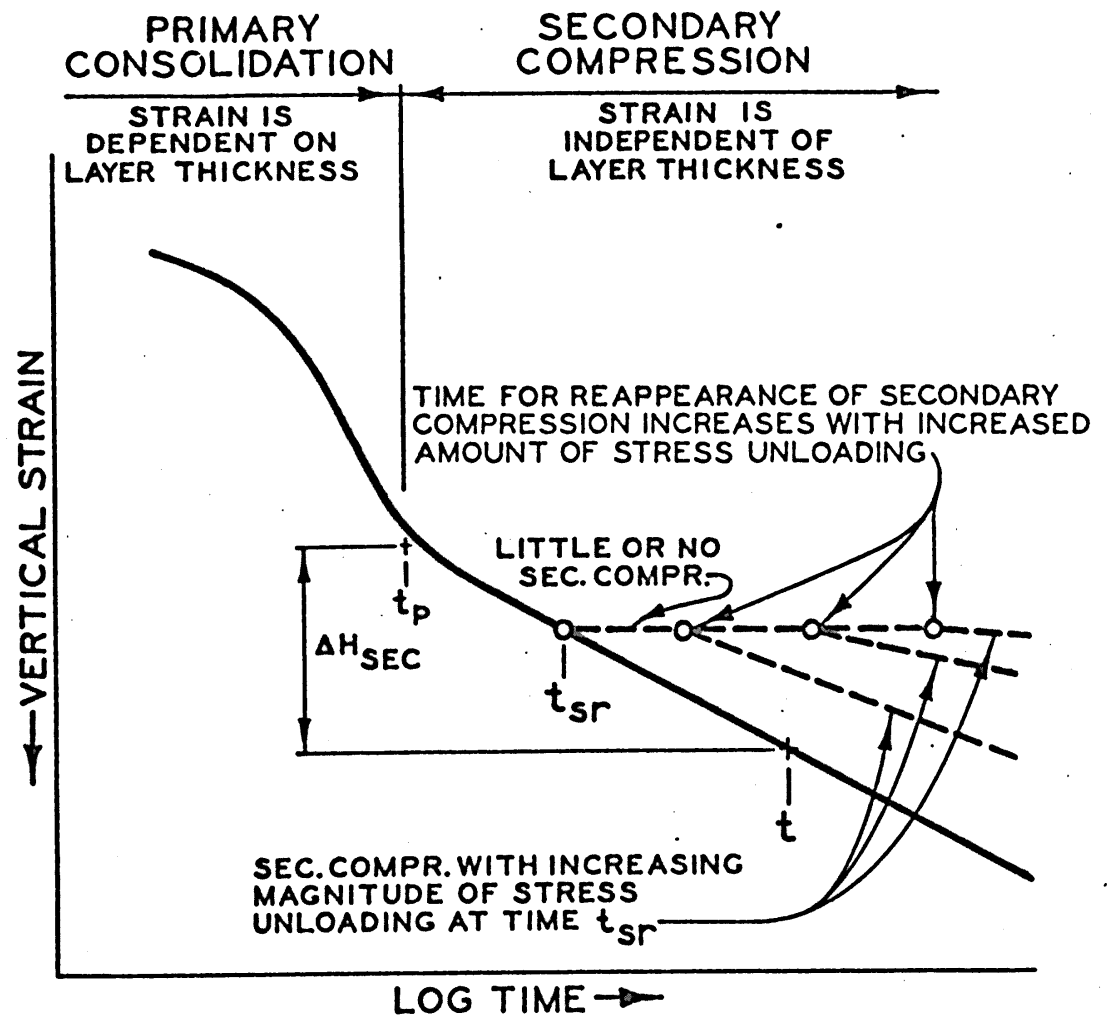

EFFECTS OF STRESS UNLOADING ON . SECONDARY COMPRESSIONLABORATORY TESTS 


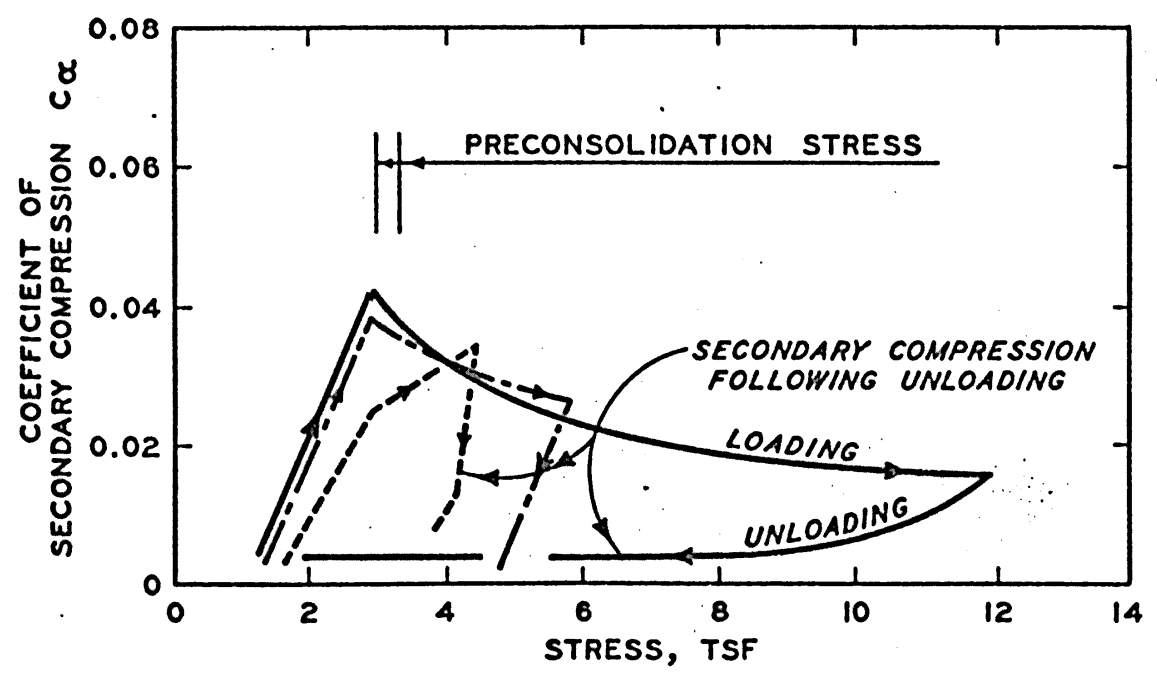

SECONDARY COMPRESSION-VARIATION OF

$C_{\propto}$ DURINGG LOADING AND UNLOADING 


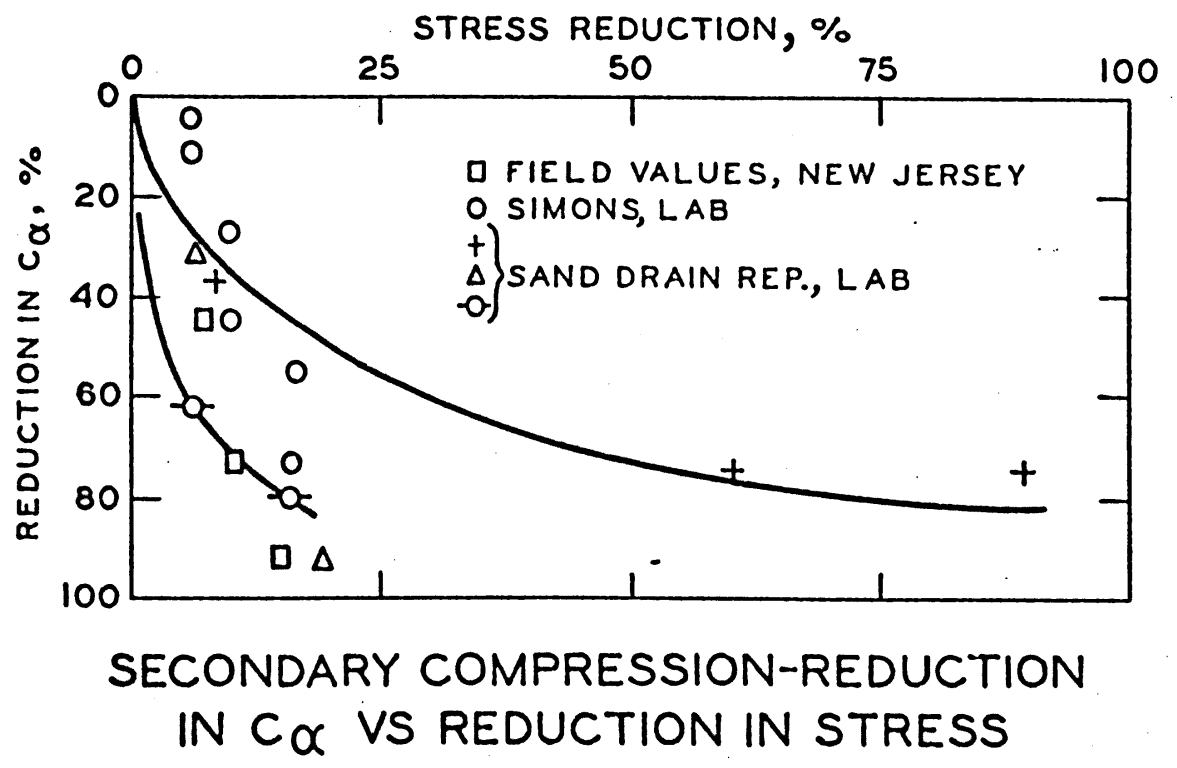




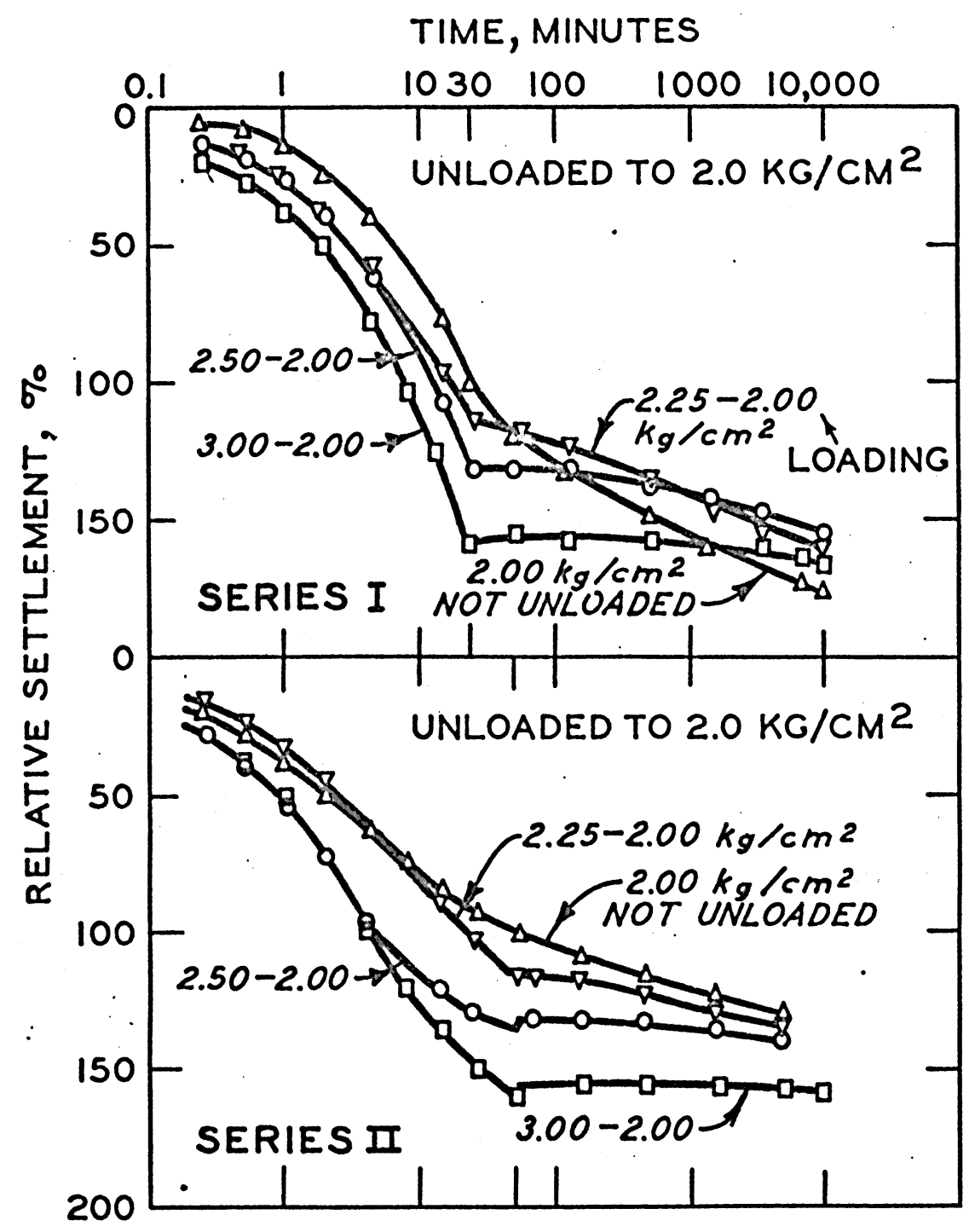

EFFECT OF STRESS DECREASE ON SECONDARY COMPRESSION LABORATORY CONSOLIDATION TESTS (AFTER SIMONS, 1964) 

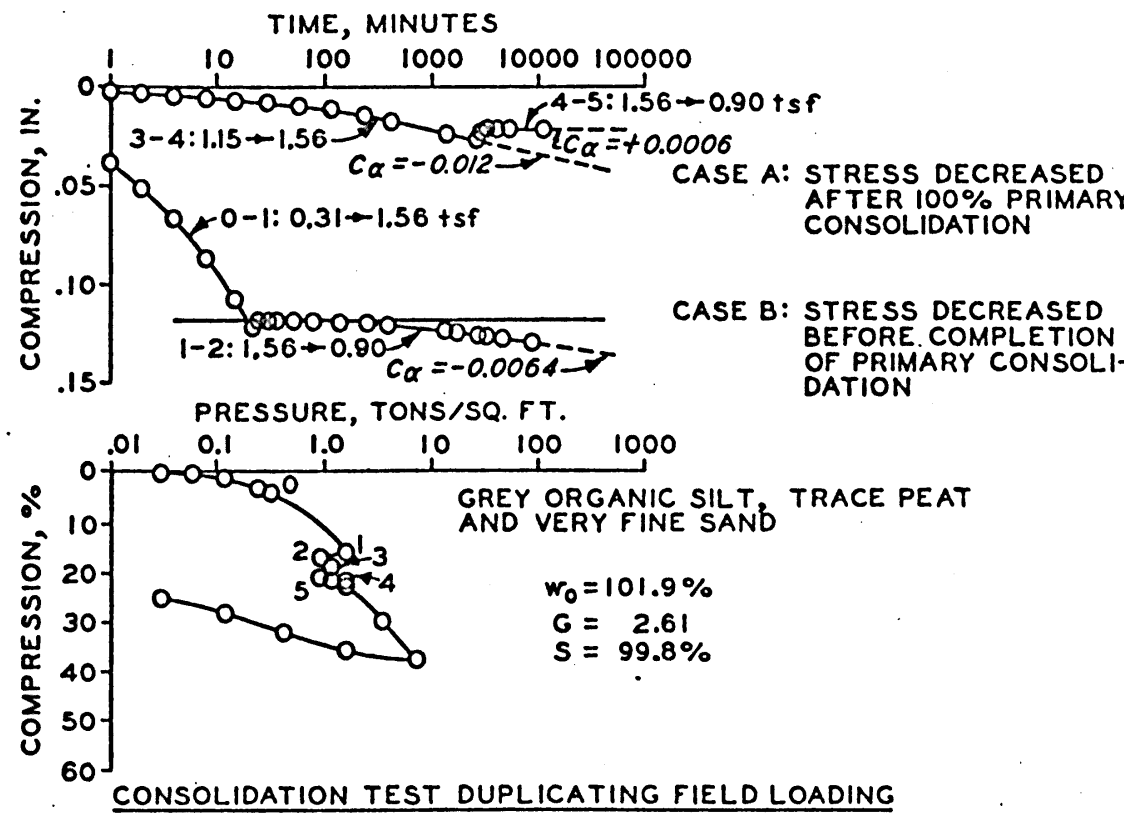

EFFECT OF STRESS DECREASE ON SECONDARY COMPRESSION-LABORATORY CONSOLIDATION TEST (AFTER KAPP ET AL) 
10, and 11 and extending over long time periods, are desirable for important precompression application. Such tests should be carried out for periods of time even longer than four to six weeks, if possible; since there may be an Increase in the slopes of deformation versus log time for very large values of time, as will be discussed subsequently. The general behavior implied by the experimental data cited is essentially consistent with deductions from Taylor's concepts. ${ }^{27}$ While much additional work is required to confirm and extend knowledge of secondary compression, for practical purposes, the concept that secondary compression can be materially reduced by temporary surcharge loading appears sound according to both laboratory tests and field observations. Correlation Charts for Subsoil Characteristics

Correlations between subsoil characteristics used in precompression design and simple soil index properties can be developed when working in a given area and often have relatively wide applicability. While they are useful for preliminary estimates and are valuable for checking purposes, they are not suitable for final design unless developed for a local area. Some correlations and references for soil properties of interest in precompression design are listed in Table 4, together with some generalized correlations derived from the references. While some of these apply to a wide range of soil types, e.g., compression index versus water content, others are more restricted and are mainly of illustrative value. The various correlations listed for the coefficient of consolidation $c_{v}$ do not agree closely. This soil property is so variable and important that only local correlations developed for a given site are considered satisfactory. As previously discussed, the coefficient of consolidation varies widely with effective stress and with its value relative to the preconsolidation stress. Published correlations that do not give the effective stress nor its relationship relative to the preconsolidation stress have only limited value. 


\section{Soil Property} (1)
Reference

(2)

\section{Specific Gravity}

(a) Virgin, normally loaded peat in British Columbia, $\mathrm{W}=100$ to 1400 percent

(b) Organic soils extending into pure peat range, Northern Ontario, Canada

(c) Approximate value for $\mathrm{w} \leq 600$ percent: $G=2.60-0.0016 \mathrm{w}, \mathrm{w}$ in percent

Voids Ratio

(a) Peat in British Columbia

$\mathrm{w}=400$ to 1500 percent

$e=0.0175 \mathrm{w}, \mathrm{w}$ in percent

\section{Compression Index}

(a) For clays and some organic soils

1. $C_{c}=0.009$ (IL - I0)

2. $C_{c}=0.011(I I-16)$

$c_{c}=0.0104 \mathrm{w}-0.043$ to $0.0256 \mathrm{w}-0.553$

3. $\mathrm{C}_{\mathrm{c}}=0.01 \mathrm{w}$ to $0.015 \mathrm{w}$, $\mathrm{w}$ in percent

4. $C_{c}=0.0054(2.6 \mathrm{w}-35), \mathrm{w}$ in percent

(b) Peat and organic soils

1. Peat in British Columbia

․ $c_{c}=0.75 \mathrm{e}$

2. Jersey Meadows

(c) General average: $C_{c}=0.013 \mathrm{w}$, $\mathrm{w}$ in percent Coefficient of Compressibility, $a_{v}$

(a). Peat and organic soils

$e<7: \log a_{v}=2.33 e-1.025$

e $>7: \log a_{v}=0.108 e-0.094$.

Coefficient of Consolidation

(a) Clay, liquid limits up to 90

(b) Clay, liquid limits up to 170

(c) Organic silts and peaty organic silts, $\mathrm{w}=50$ to 350 percent
Lea and Brawner 28

MacFarlane 29

Lea and Brawner 28

Terzaghi and Peck 30

WES 31

Moran et al. ${ }^{2}$

Nishida in 2ef. 12

Lea and Brawner 28

Kapp et al. 26

Lea and Brawner 28

Terzaghi and Peck 30

Navy Design Manual 12

(Fig. 3-6)

Kapp et al.26 
TABLE 4 (Continued)

Soil Property

(I)

Reference

(2).

Swelling Index

(a) For silts and clays with liquid limits to 170

Coefficient of Secondary Compression, $c_{\alpha}$

(a) $c_{\alpha}$ versus moisture content

For $w<200$ percent, $c_{\alpha}=0.00015 \mathrm{w}, \mathrm{w}$ in percent

For $\mathrm{w}>200$ percent, $c_{\alpha}=0.026+0.00002 \mathrm{w}$,

Navy Design Manual ${ }^{12}$

(Fig. 3-5)

Navy Design Manual 12 
Correlations for the coefficient of secondary compression $\varepsilon_{\alpha}$ are of special interest and, because they will be discussed subsequently, are shown in Fig. 12. The various correlations between $c_{\alpha}$ and water content are approximately equal to:

$$
\begin{aligned}
& \text { For } \mathrm{w}<200 \%, c_{\alpha}=0.00015 \mathrm{w} \% \\
& \text { For } \mathrm{w}>200 \%, c_{\alpha}=0.026+0.00002 \mathrm{w} \%
\end{aligned}
$$

These correlations are based on laboratory values determined from one-dimensional consolidation tests and may not apply where lateral strain occurs and shearing stresses are higher. The coefficient of secondary compression for peaty soil having extremely high water contents does not become extremely large, as shown by Fig. 12, which is consistent with other data for higher water contents. This is significant because of the impression that secondary compression of peaty soil is so large as to make precompression inapplicable. The coefficient of secondary compression (see Fig. 12a) is decreased by disturbance, whereas some writers have stated, without proof, that secondary compression is increased by disturbance. 


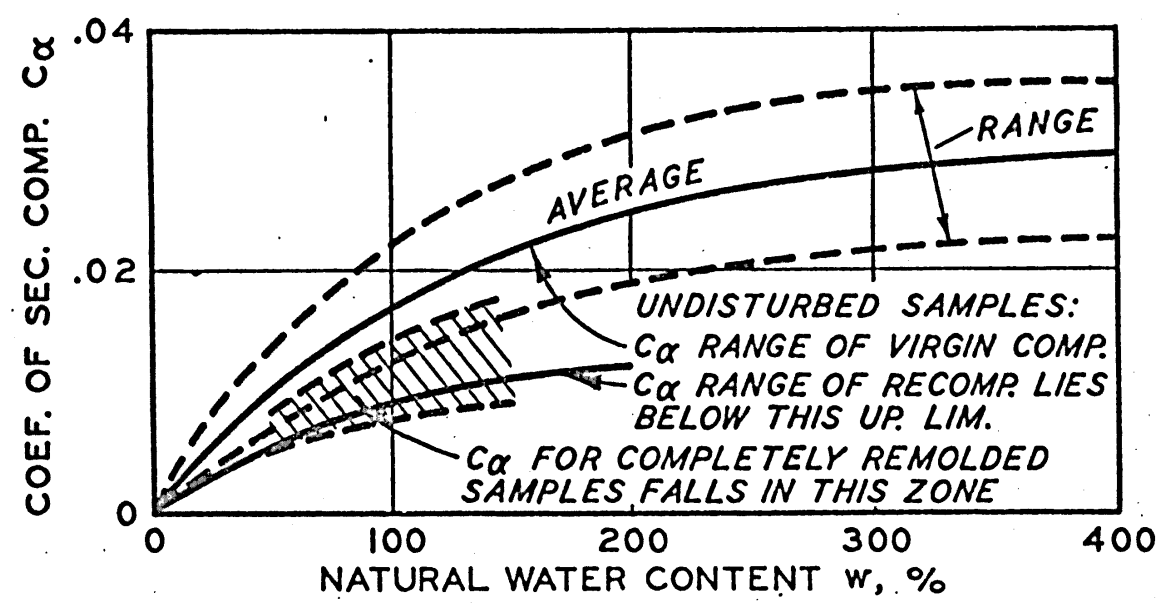

a. $C_{\alpha}$ VS W

NAVY DESIGN MANUAL DM-712 (AFTER GOULD)

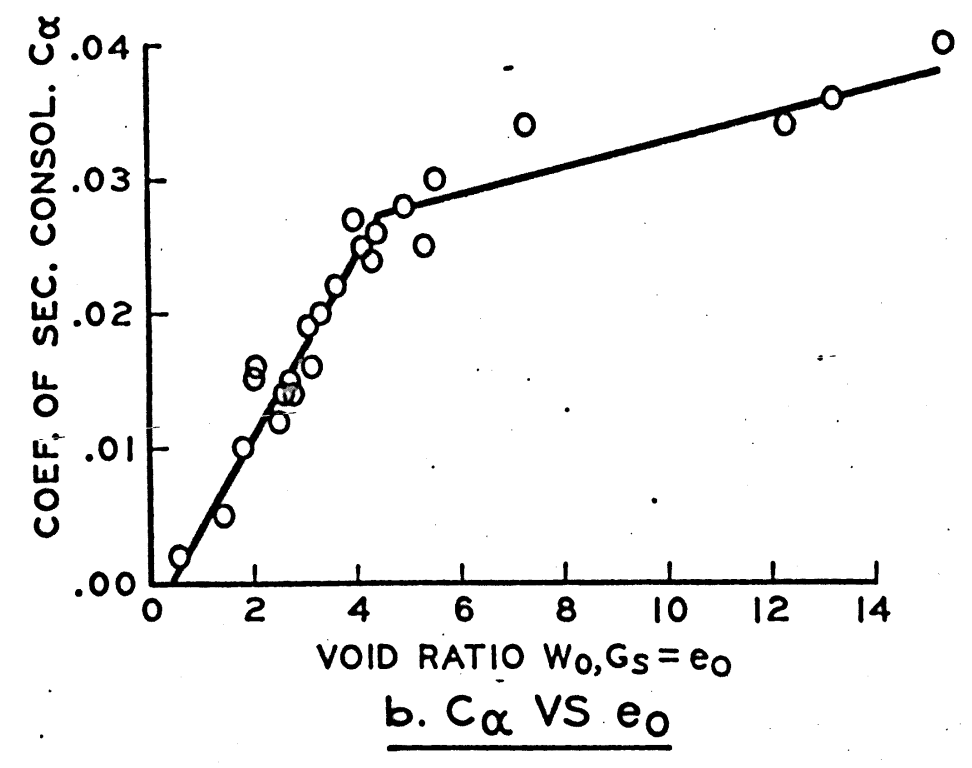

(AFTER KAPP ET AL)

COEFFICIENT OF

SECONDARY COMPRESSION VS

WATER CONTENT AND VOID RATIO

Fig. 12 
Primary Consolidation

Since Terzaghi's original presentation of consolidation theory for vertical settlements and vertical drainage, the fundamental theory has been expanded to include two- and three-dimensional drainage, and the effects of contiguous unlike layers of soil, gradual application of load, variation of permeability, and of other factors. Some of these cases are listed in Table 5 for reference. Recent work has considered primary and secondary compression as a combined and continuous process. While this may be essential for developing improved theories, it still appears advantageous for practical design. purposes to consider these as separate phases. Terzaghi's deduction that the effect of uniform load application could be replaced by an instantaneous application of the total load at one-half the loading period has proven substantially correct.

While use of newer concepts, including pore pressure coefficients in settlement analyses, as proposed by Skempton and Bjerrum, ${ }^{45}$ and Lambe's stress path method, ${ }^{46}$ may add to accuracy and understanding, a careful evaluation of subsoil consolidation characteristics, using both field observations and laboratory consolidation tests, is considered more important than effects of limitations of the Terzaghi consolidation theory. While the improvements in consolidation theory merit serious consideration, uncertainties in input data are considered major sources of error. Improved theories better fitting actual subsoil conditions and use of numerical solutions are undergoing rapid development.

Surcharge Loading to Compensate for Primary Consolidation

Computational procedures for achieving precompression through use of 
a. CONSOLIDATION THEORY - GENERAI

Continguous unlike layers -

Numerical methods for unlike layers

Time dependent loading and varying permeability

Multilayered soils

Varying permeability and compressibility

Nonlinear consolidation theory

Finite nonlinear consolidation

Primary and secondary consolidation

Primary and secondary consolidation
Gray $^{32}$

Harr, ${ }^{33}$ scott ${ }^{34}$

Schiffman 35

Abbott 36

Schiffman and Gibșon ${ }^{37}$

Davis and Raymond 38

Gibson, and others 39

Barden 40

deJong 41

b. PARTIALLY SATURATED SOILS

Moran, and others ${ }^{2}$ (Gould)

Yoshimi and Osterberg 42

Barden 43

Rowe and Barden 44 
preload fills where sand drains are used to accelerate consolidation are described in Reference 2. These procedures are summarized in the Navy Soil Mechanics Design Manual DM-7, ${ }^{12}$ where they are extended to the case without sand drains. A minor and obvious change required for preloading design without sand drains was not pointed out, but was subsequently described by Aldrich. ${ }^{1}$ However, because some confusion persists, as evidenced by comments at the ASCE conference at MIT in August 1968, the method is summarized below for the case where precompression is intended to eliminate all primary consolidation expected under permanent loadings. (Partial compensation for primary consolidation is discouraged as being generally unsound.) The procedure where sand drains are used is described in a companion paper 47 and in Reference 2. The concept of using a temporary preload or surcharge fill is illustrated in Fig. 13. It consists of applying a temporary load in excess of permanent loading, thereby causing more settlement to occur at any given time than would be caused only by permanent loading. When sufficient settlement has resulted, the surcharge load is removed. It is obvious from Fig. 13 that the surcharge load can be removed when the compressible stratum is only partiaily consolidated under the permanent plus surcharge loading; indeed, this is the purpose of applying the surcharge. .

When the surcharge load is removed, the central portion of a uniform compressible stratum will be consolidated less than the average for the entire stratum and portions adjacent to the top and bottom of the stratum will be consolidated more than the average, as illustrated in Fig. 14 for an average degree of consolidation of 50 percent. If the average degree of consolidation is used as the criterion for surcharge load removal, the central portion of the compressible stratum would be underconsolidated and would continue to settle, whereas the outer portions would be overconsolidated and would tend 

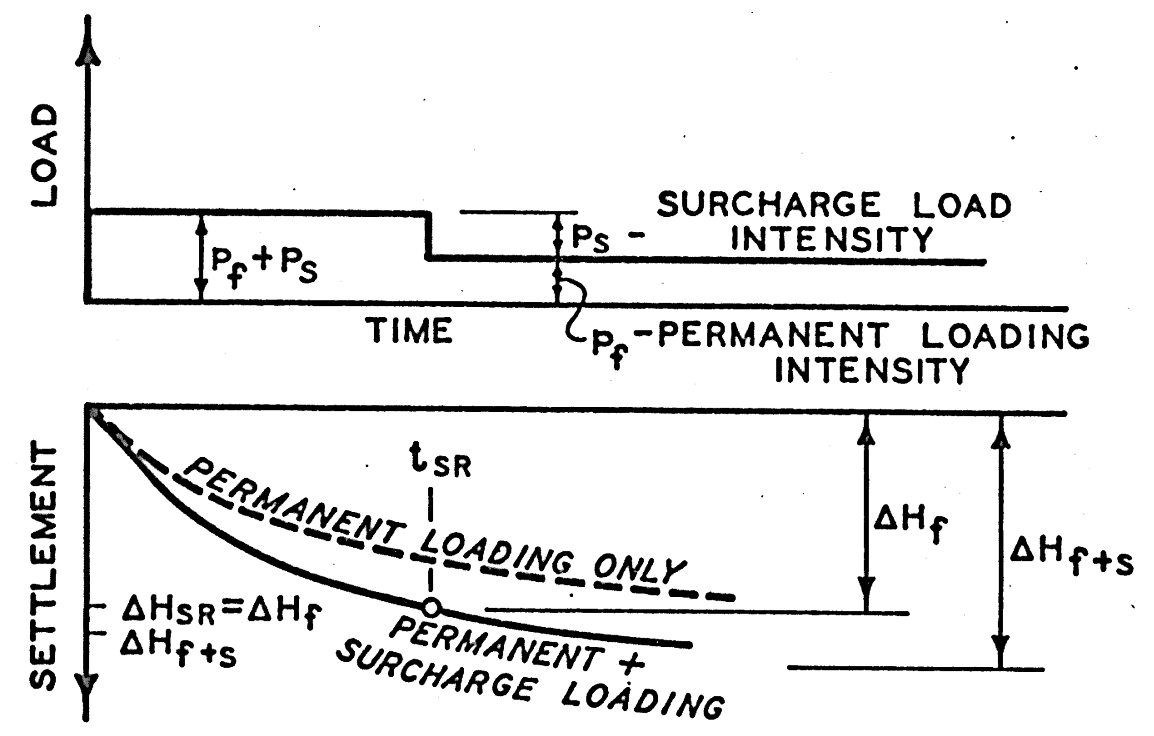

RELOADING DESIGN COMPENSATION FOR PRIMARY SETTLEMENT BY TEMPORARY SURCHARGE FILL

Fig. 13

37 


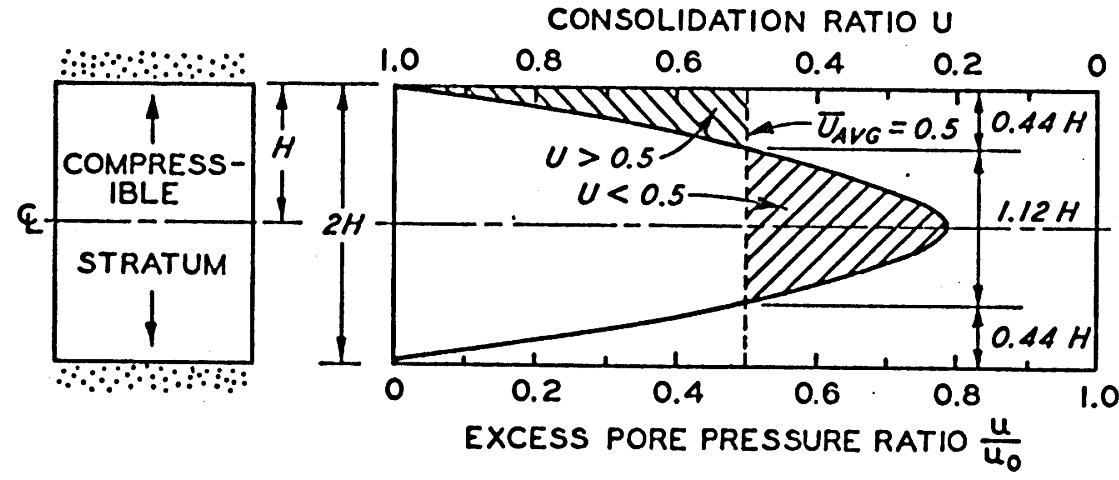

EXCESS PORE WATER PRESSURE AND DEGREE OF CONSOLIDATION WHEN AVERAGE DEGREE OF CONSOLIDATION IS 50 PERCENT 
to swell or expand. While these opposite effects would tend to counterbalance each other, settlement would exceed swelling, since the compression index for consolidation exceeds substantially that for swelling. It appears advisable, therefore, to use the degree of consolidation at the center of the compressible stratum as the criterion for removal of the surcharge load, although this is somewhat conservative.

When using the degree of consolidation at the center of the compressible stratum as the criterion for surcharge load removal, it is apparent that Fig. 13 refers to settlement of the I-ft-thick layer at the center of the stratum; i.e. to strain. Also, the excess pore-water pressure and degree of consolidation at the time of surcharge load removal apply to the center of the compressible stratum and not to average values for the entire stratum. Based upon these concepts and by referring to Fig. 13, the required degree of consolidation at the center of the layer when the surcharge load is removed is:

$$
U_{f+s} \Delta H_{f+s}=\Delta H_{f}
$$

or

$$
U_{f+s}=\frac{\Delta H_{f}}{\Delta H_{f+s}}
$$

$\Delta \mathrm{H}_{\mathrm{f}}$ and $\Delta \mathrm{H}_{\mathrm{f}+\mathrm{s}}$ refer to settlement of the l-ft-thick layer at the center of the compressible stratum. If the compressible stratum is normally consolidated:

$$
\Delta H_{f}=\frac{(H=I)}{I+e_{0}} C_{c} \quad \log _{10}\left(\frac{p_{0}+p_{f}}{p_{0}}\right)
$$

and

$$
\Delta_{\mathrm{H}+\mathrm{S}}=\frac{(\mathrm{H}=\mathrm{I})}{1+\mathrm{e}_{0}} C_{c} \log _{10}\left(\frac{\mathrm{p}_{0}+\mathrm{p}_{\mathrm{f}}+\mathrm{p}_{\mathrm{S}}}{\mathrm{p}_{0}}\right)
$$


Therefore, the required degree of consolidation at the midpoint of the compressible stratum at the time of surcharge load removal is:

$$
U_{f+s}=\frac{\log _{10}\left(1+\frac{p_{s}}{p_{0}}\right)}{\log _{10}\left(1+\frac{p_{f}}{p_{0}}+\frac{p_{s}}{p_{0}}\right)}
$$

or

$$
U_{f+s}=\frac{\log _{10}\left(1+\frac{p_{f}}{p_{o}}\right)}{\log _{10}\left[1+\frac{p_{f}}{p_{0}}\left(1+\frac{p_{s}}{p_{f}}\right)\right]}
$$

Values of the required degree of consolidation at the center line of the compressible stratum can be obtained from Eq. 4 or Fig. 15 for normally consolidated soils. The procedure for preconsolidated soils is similar. When $U_{f+s}$ has been determined for assumed values of surcharge intensity $p_{s} / p_{f}$ and known values of permanent loading ratio $p_{f} / p_{0}$ the corresponding time factor $T_{v}$ can be obtained from readily available charts in standard texts, or from Fig. 16 for $\frac{z}{\mathrm{H}}=1.0$. The time for syrcharge removal $t_{s r}$ can then be computed in the usual manner from $t_{s r}=\frac{T_{v} H}{c_{v}}$. In many cases the time for surcharge load removal is predetermined and the above procedure is reversed to find the requirec surcharge loading ratio $\mathrm{p}_{\mathrm{s}} / \mathrm{p}_{\mathrm{f}}$.

The simplified loading condition used in Fig. 13 to illustrate basic concepts applies to highway, airfield, and other similar work, when $p_{f}$ correspondsto final or permanent loadings. However, where structures are to be constructed, It is necessary to compute stresses from foundation and local floor loadings at several depths within the compressible stratum, as conditions at the center of the compressible stratum may not then govern precompression design. Column footings may cause hardly any stress increase at the center of the compressible stratum, although the stress increase near the top of the stratum may be 


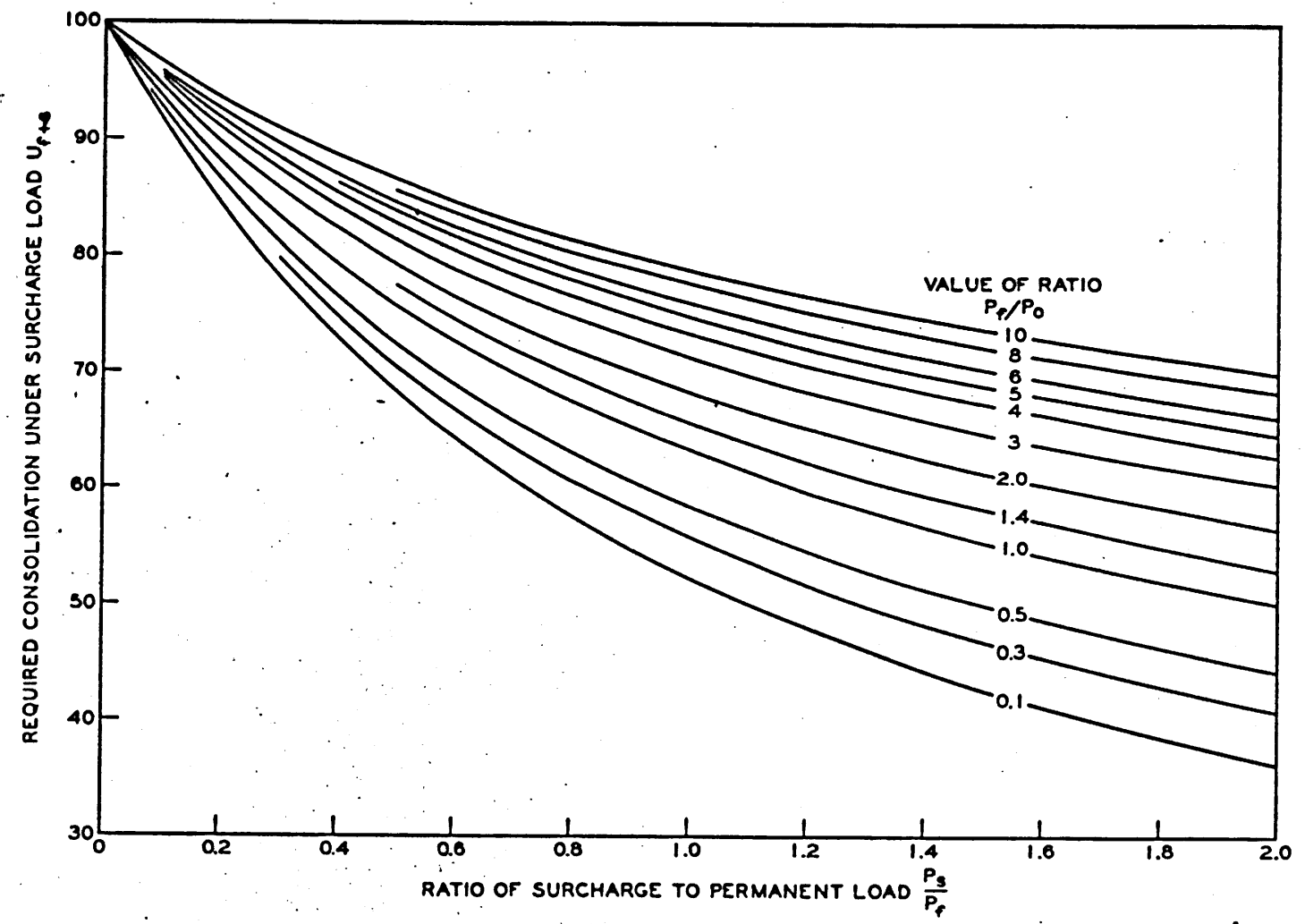

PRECOMPRESSION TO ELIMINATE PRIMARY CONSOLIDATION 


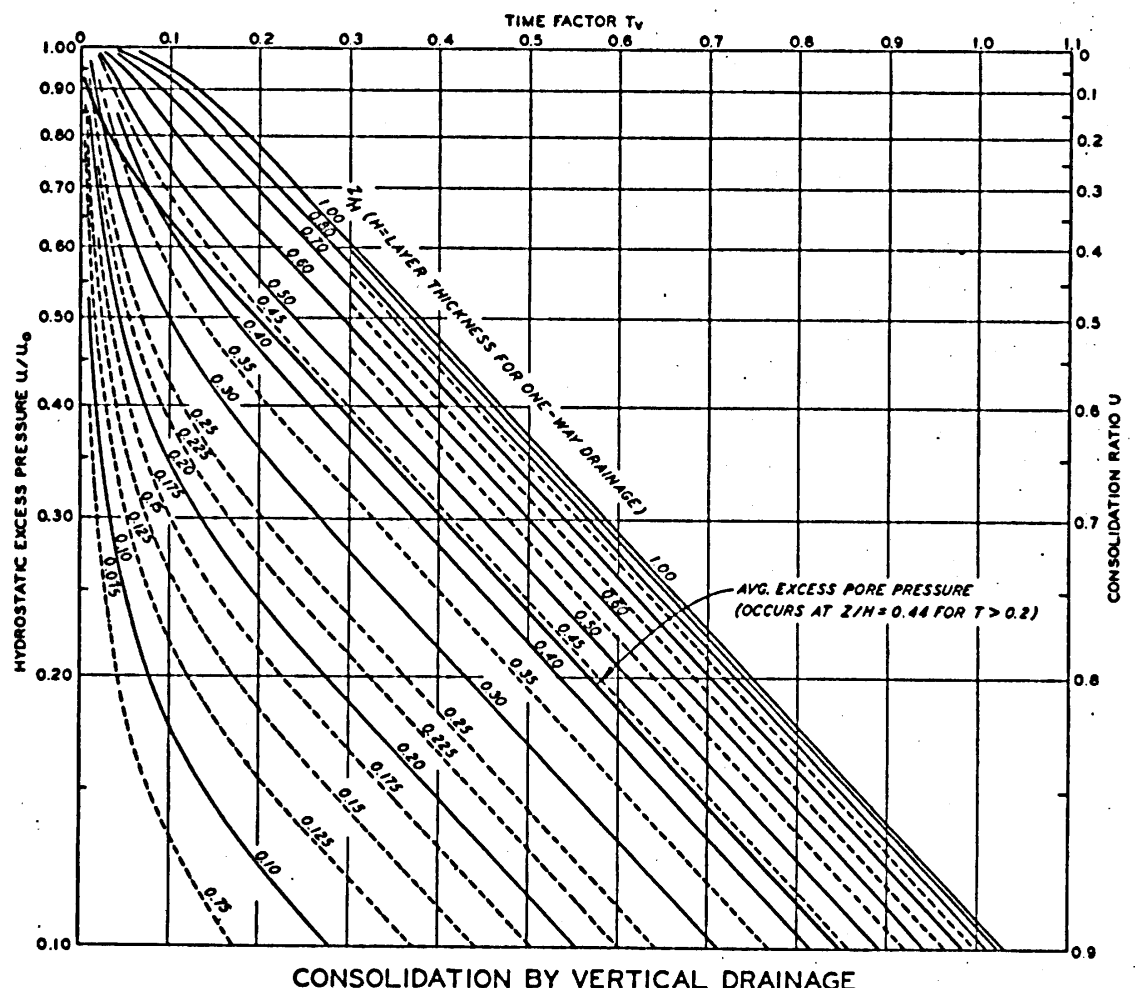

HYDROSTATIC EXCESS PRESSURE AS FUNCTION OF TIME FACTOR TV AND POSITION $Z / H$ 
considerable. It is desirable, therefore, to use low footing bearing pressures, thereby minimizing the amount of surcharge load required. A minimum thickness (5 ft or more) of good fill over the compressible stratum should generally be provided. Stress distribution from footing loads should be computed assuming a uniform elastic material. Layered system action and associated benefits should not be assumed unless shear stresses in and between the various layers are investigated, and this is hardly warranted for precompression design. In addition, where structures are constructed, recompression settlements caused by addition of structure loadings should be computed. In order to minimize rebound following surcharge load removal, the magnitude of $p_{f}$ should preferably not be less than about one-third $p_{s}$, the surcharge load intensity.

The above outline of the design procedure is presented in the simplest possible form for illustrative purposes. Limitations and modifications to account for more complex conditions are believed obvious and are not discussed because of space limitations. It may be appropriate, however, to warn against computing the required degree of consolidation at the time of surcharge load removal as $U=\frac{p_{f}}{p_{f}+p_{s}}$. This assumption is satisfactory only where increased loadings are small.

Secondary Compression Settlements General Considerations

When using precompression techniques, it is customary to attempt to eliminate all settlements that might result from primary consolidation prior to construction of a structure. While these settlements may amount to 1 to 6 ft or more, they occur before the structure or pavement is constructed. If primary consolidation is eliminated, construction and postconstruction settlement of a structure would consist of slight recompression as structure loads are applied, which can be estimated in a conventional manner, and subsequent settlement resulting. 
from secondary compression. Because settlements resulting from secondary compression may amount to as much as $1 / 2$ to $1-1 / 2$ ft during the economic life of a structure, they generally should be considered in design. While these settlements cannot be fully prevented, they can be reduced through surcharge loading to amounts considered tolerable. It appears appropriate, therefore, to summarize briefly some practical concepts regarding secondary compression, while at the same time emphasizing that the current knowledge of secondary compression is highly limited and that design improvements are expected. Despite this, the concepts and procedures described are believed suitable for design purposes when used conservatively.

It has been reasonably well established that for most soils, the rate of secondary compression decreases with time in a logarithmic manner and also that the magnitude of secondary compression is essentially directly proportional to thickness of the compressible stratum at the start of secondary compression. Secondary compression appears to result from shear stresses, as illustrated in Fig. 17 where isotropic consolidation caused practically no secondary compression, whereas one-dimensional consolidation did. ${ }^{48}$ The coefficient of secondary compression used in precompression design is determined for complete lateral confinement, such as found in a laboratory consolidation test and beneath the central portion of wide fills. Since secondary compression appears to result from shear stresses, it seems possible that secondary compression settlements beneath the edges of fills or loaded areas where shear stresses are high may exceed values beneath the central portion of preload fills. As discussed previously, the magnitude of secondary compression in poor soils such as peats and other materials is not inordinately large (see Fig. 12), although it is generally more erratic than for other materials.

As a result of concepts discussed and considering secondary compression to 


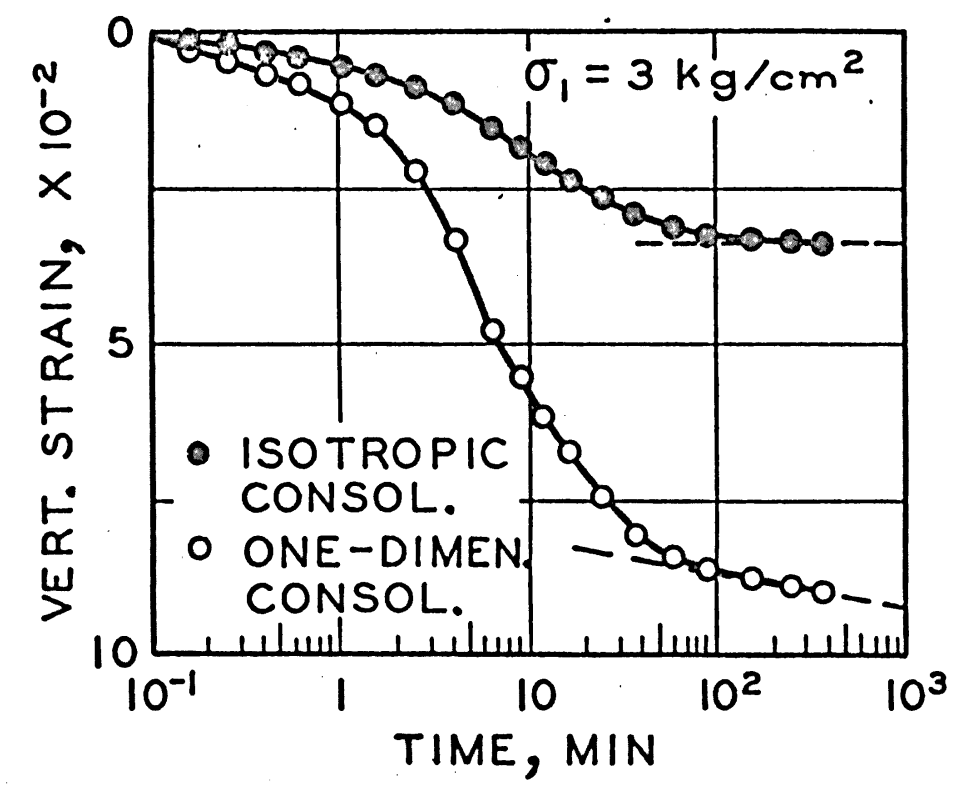

\section{SECONDARY COMPRESSION ISOTROPIC AND ONE - \\ DIMENSIONAL CONSOLIDATION (AFTER AKAI AND ADACHI)}


start upon completion of primary consolidation, the magnitude of secondary compression that would occur following completion of primary consolidation can be computed ${ }^{2}$ as:

$$
\Delta \mathrm{H}_{\text {sec }}=c_{\alpha} \mathrm{H}_{\mathrm{p}} \log \frac{t}{t_{p}}
$$

Where

$$
\begin{aligned}
\Delta H_{\text {sec }}= & \text { settlement from secondary compression } \\
c_{\alpha}= & \text { coefficient of secondary compression } \\
H_{p}= & \text { total thickness of compressible stratum at time } t_{p} \\
t_{p}= & \text { time corresponding to completion of primary } \\
& \text { consolidation } \\
t \quad & \text { time at which secondary compression settlement } \\
& \text { is to be computed }
\end{aligned}
$$

Surcharge Loading to Compensate

Partially for Secondary Compression

Current concepts ${ }^{2}$ of precompression design to reduce postconstruction settlements resulting from both primary consolidation and secondary compression are based largely upon a working hypothesis presented by Taylor ${ }^{27}$ in 1942. Despite the impressive advances in representing primary consolidation and secondary compression as a combined process, it appears advantageous for design purposes to consider these as separate phases. If this is done, the simple figure constructed by Taylor (see Fig. 18), effectively shows design concepts involved and was the basis for the design procedure presented in Reference 2 in 1958; it was also recently used by Bjerrum. 49

Taylor proposed, in effect, that secondary compression under various constant effective stresses would result in constant time lines of the general nature shown in Fig. 18. While he constructed the time lines parallel to the primary compression line and while today they might be constructed nonparallel, this is insignificant from the conceptual viewpoint. The significant feature of Fig. 18 is the implication that a surcharge load can cause a total settlement equal to 


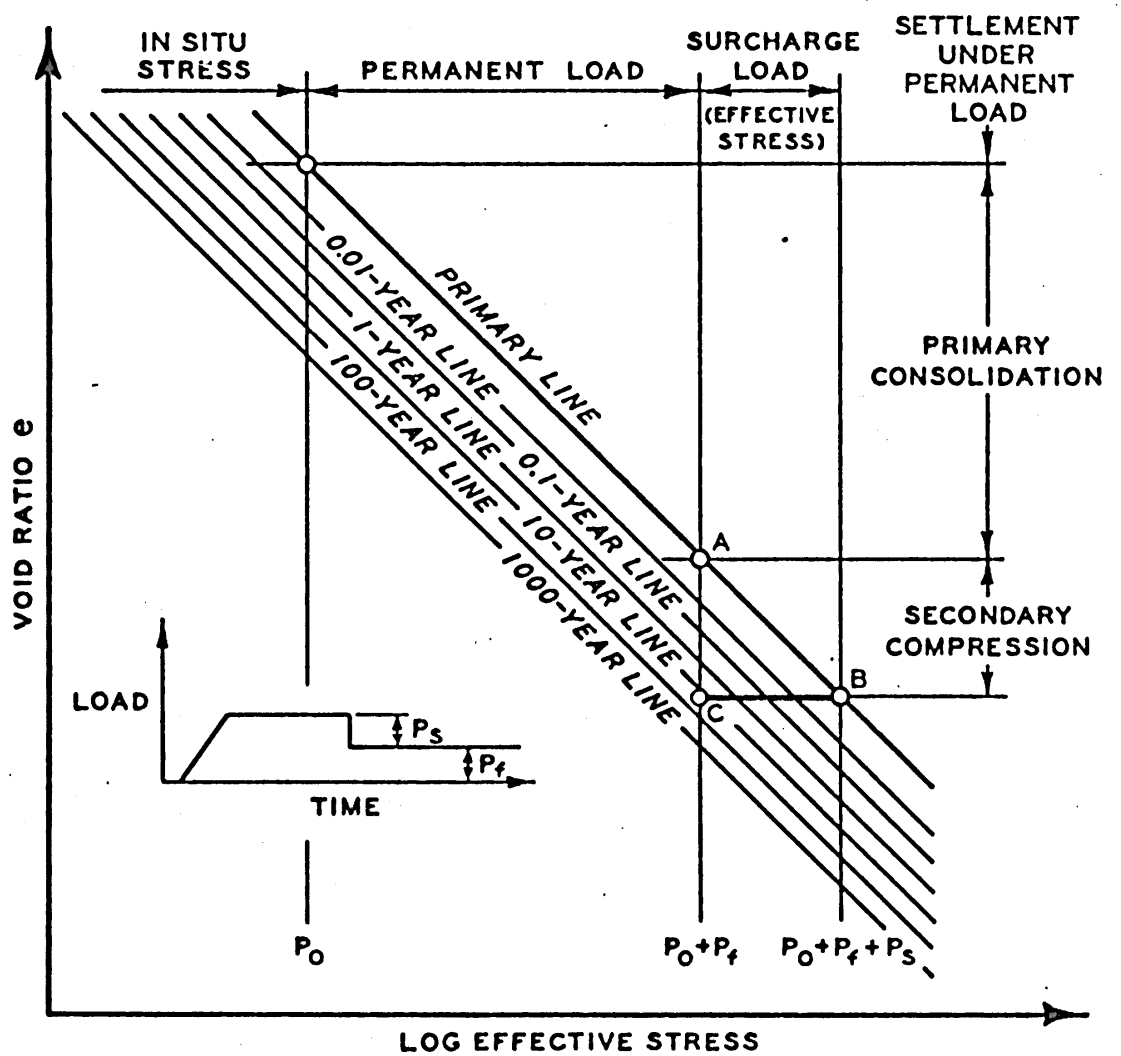

SURCHARGE LOADING TO REDUCE SECONDARY COMPRESSION

NORMALLY CONSOLIDATED DEPOSITS

(BASED UPON TAYLOR CONCEPTS - 1942) 
100 percent primary consolidation plus such amount of secondary compression under permanent loading as the engineer feels must be removed to make remaining secondary compression settlements tolerable.

The reasoning that preloading reduces secondary compression after removal of the preload is now supported by (1) direct experimental evidence from laboratory tests, as previously discussed and as indicated in Reference 2 . and in Figs. 7 through 1l; (2) field evidence, both published ${ }^{2,23}$ and unpublished; and (3) indirect experimental evidence from laboratory tests, which follows the following concepts.

The ratio of $\sigma_{\mathrm{h}} / \sigma_{\mathrm{v}}$ during primary consolidation under the permanent plus surcharge loads (see point B in Fig. 18) increases when the preload is removed and the subsoil suddenly becomes, in effect, an overconsolidated material (see point C). For example, according to Brooker and Ireland, 50 the ratio of . $\sigma_{1} / \sigma_{3}$ is about 1.5 for a normally consolidated clay having a plasticity index of 50 (see points $A$ and $B$ in Fig. 18). This ratio decreases when the surcharge load is removed (see point C in Fig. 18) and is about 1.2 for an overconsolidation ratio (OCR) of 1.5 and is about 1.0 for an OCR of approximately 2.8 . Since it is generally accepted that secondary compression is either largely or entirely dependent upon existence of shear stresses and since overconsolidation achieved under surcharge loading decreases shear stresses under permanent loading, precompression to effective stresses in excess of final design loadings should decrease postconstruction secondary compression. . The reduction in secondary compression may be somewhat less beneath footings and beneath permanent slopes where shear stresses will be higher than beneath the central portion of large precompressed areas. This can be investigated during design of a project.

The procedure when working with preconsolidated materials (see Fig. 19) in-: volves no special difficulties. Taylor's diagram implies that overconsolidation 


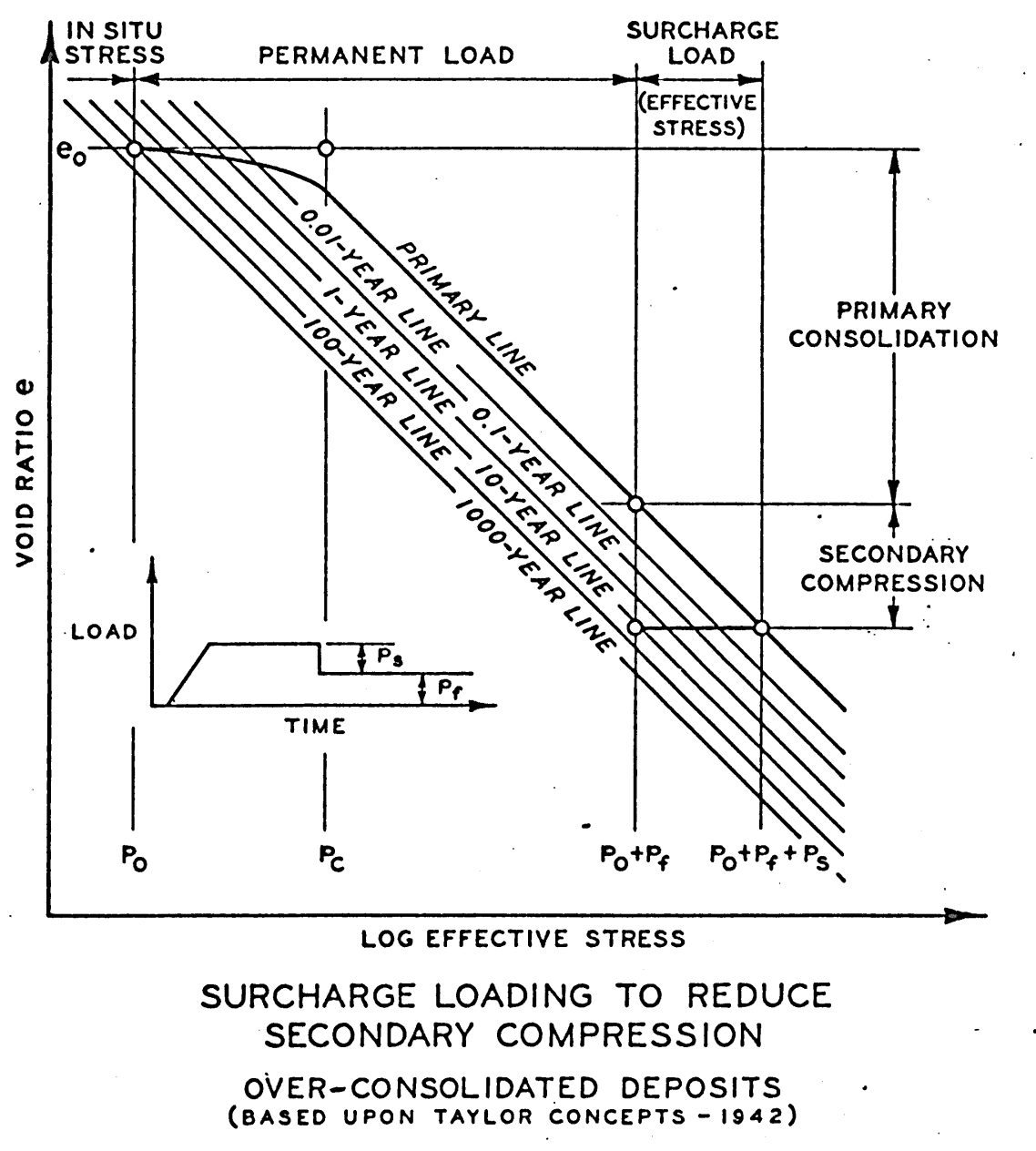

Fig. 19

49 
can result solely from long-term secondary compression. When the surcharge load is removed, there will be a small amount of swelling, generally in accordance with results of laboratory consolidation tests in which stress unloading occurs. When permanent structure loads are applied, some small recompression wili occur, but design for these effects involves no special consideration.

\section{Design for Secondary Compression}

Application of the above concepts to design of surcharge fills to compensate partially for secondary compression is illustrated in Fig. 20. The settlement at time of surcharge load removal $t_{s r}$ is:

$$
\Delta \mathrm{H}_{\mathrm{Sr}}=\Delta \mathrm{H}_{\mathrm{f}}+\Delta \mathrm{H}_{\mathrm{sc}}
$$

Where $\Delta \mathrm{H}_{\mathrm{Sc}}$ is the amount of secondary compression to be eliminated, or compensated for, during surcharge loading,

$$
\text { Also, } \quad \Delta \mathrm{H}_{\mathrm{sr}}=\mathrm{U}_{\mathrm{f}+\mathrm{s}} \times \Delta \mathrm{H}_{\mathrm{f}+\mathrm{s}}
$$

Therefore, the required degree of consolidation at the center line of the compressible stratum at the time of surcharge load removal is:

$$
U_{f+s}=\frac{I}{\Delta H_{f+s}}\left[\Delta H_{f}+\Delta H_{s c}\right]
$$

or,

$$
U_{f+s}=\frac{2}{\Delta H_{f+s}}\left[\Delta H_{f}+c_{\alpha}\left(H-\Delta H_{f}\right) \log _{10} \frac{t_{s c}}{t_{p}}\right]
$$

If subsoils are normally consolidated, values for $\Delta H_{f}$ and $\Delta H_{f+s}$ are given by Eq. 2 and 3 and $U_{f+s}$ becomes ${ }^{*}$

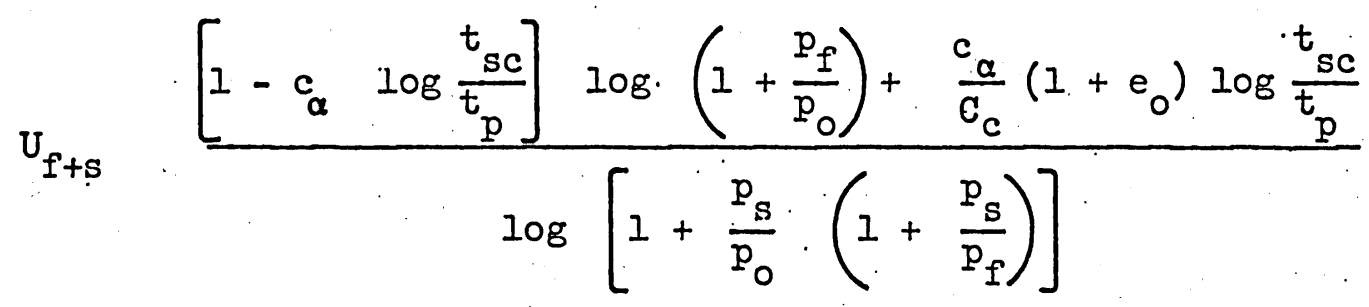

This equation, as given in Reference 2 , contains typographical errors which were corrected in Reference 12 . 

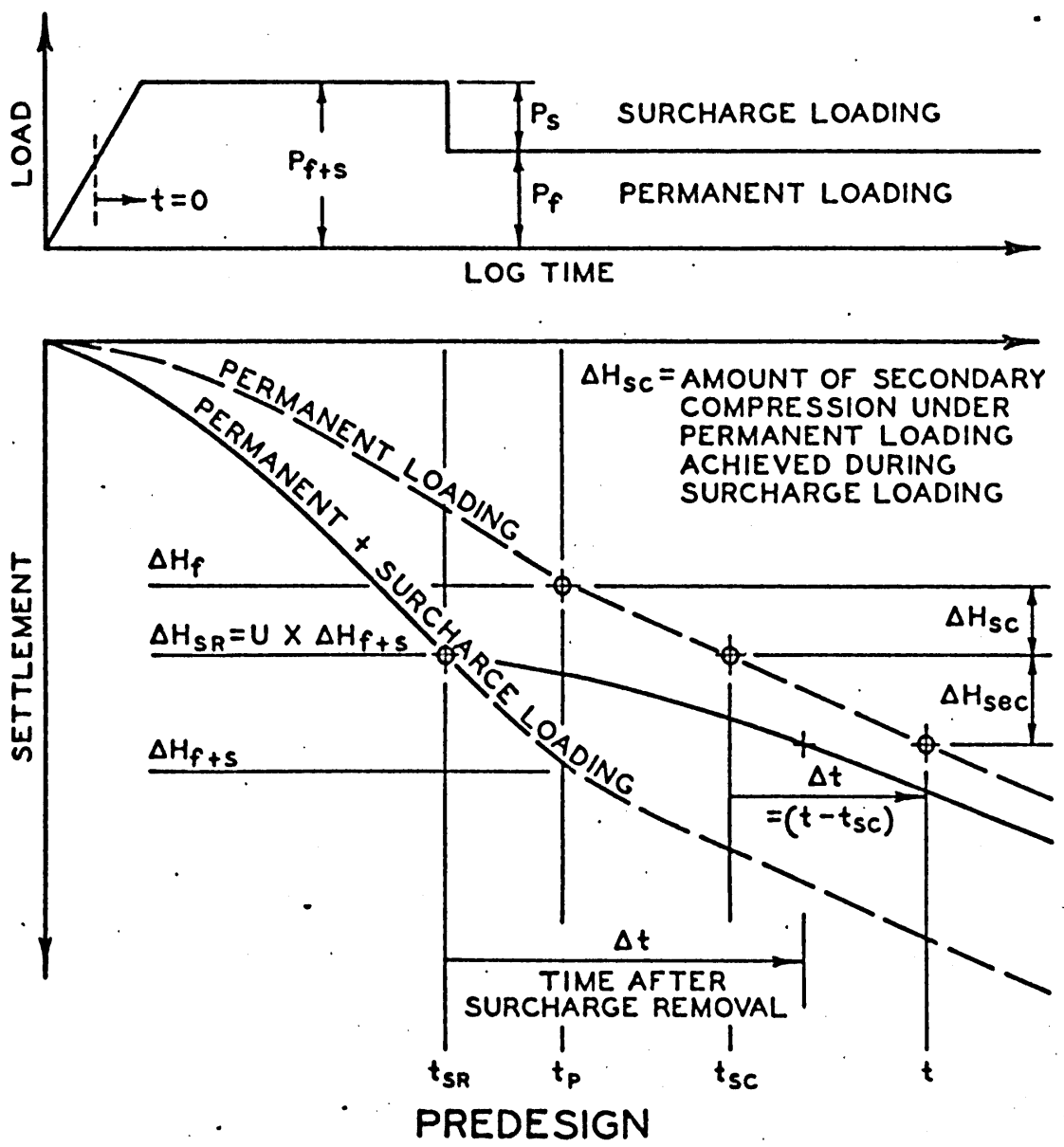

PARTIAL COMPENSATION FOR SECONDARY COMPRESSION BY TEMPORARY SURCHARGE LOADING 
This equation gives the consolidation required under surcharge loading at the center of the compressible stratum to produce a settlement equal to that produced by primary consolidation under final design loadings plus additional secondary compression equal to the amount that would otherwise occur in the time interval $t_{s c}-t_{p}$, where $t_{s c}$ is determined by the useful life of the structure or by the amount of secondary compression for which compensation. is desired. Eq. 7 can also be expressed as:

$$
U_{f+s}=U_{p}+U_{S}
$$

Where

$$
\begin{aligned}
U_{f+S}= & \text { degree of consolidation required under surcharge } \\
& \text { fill loading to produce primary consolidation plus } \\
& \text { the desired amount of secondary compression } \\
& \cdot \\
U_{p} \quad= & \text { degree of consolidation required under surcharge } \\
& \text { loading to produce settlement equal to primary } \\
& \text { consolidation } \\
U_{\mathrm{S}}= & \text { additional consolidation under surcharge loading to } \\
& \text { compensate for desired amount of secondary compres- } \\
& \text { sion settlement, } \Delta_{\mathrm{H}}
\end{aligned}
$$

The additional percent consolidation under surcharge loading to compensate partially for secondary compression can also be expressed as:

or

$$
U_{s}=U_{p} c_{\alpha}\left[\frac{1}{\frac{c_{c}}{I+e_{0}} \log \left(1+\frac{p_{f}}{p_{o}}\right)-}-I\right] \log \frac{t_{s c}}{t_{p}}
$$

$$
U_{s}=U_{p} c_{\alpha}\left(\frac{I}{\varepsilon}-1\right) \log \frac{t_{s c}}{t_{p}}
$$

Where $\varepsilon=$ the strain at the center of the compressible stratum caused by primary consolidation under the permanent loading 
Therefore, the required degree of consolidation under the surcharge loading to compensate for primary consolidation and partially for secondary compression is:

$$
U_{f+s}=U_{p} \quad\left[I+c_{\alpha}\left(\frac{I}{\varepsilon}-I\right) \log \frac{t_{s c}}{t_{p}}\right]
$$

or approximately

$$
U_{f+s}=U_{p} \quad\left[i+\frac{c_{\alpha}}{\varepsilon} \log \frac{t_{s c}}{t_{p}}\right]
$$

The ratio of $U_{s}$ to $U_{p}$ depends only on soil properties, final design loadings, and the amount of secondary compression that is to be eliminated by surcharge loading.

The above discussion referred to conditions existing at the center of the compressible stratum, which is conservative. If the degree of consolidation is just sufficient to develop effective stresses at the center equal to those caused by final loadings, the outer portions of the compressible stratum will be more highly consolidated, as indicated in Fig. 21. Thus, while secondary compression may occur in the normal manner in the central part of the stratum, It will be greatly reduced near the outer édges where effective stresses are larger than final loadings. The required effective stress $\bar{p}$ to eliminate secondary compression normally developed in a time interval $\frac{t_{\mathrm{SC}}}{t_{\mathrm{p}}}=15$ is shown in Fig. 2l. It is evident that precompression to the stress $\bar{p}$ at the center of the stratum would be relatively conservative, except where sand drains are used.

It is necessary, in the above procedure, to determine what postconstruction settlements can be tolerated. Compensation for one cycle of secondary compression, 1.e., $\frac{t_{s c}}{t_{p}}=10$, subsequent to completion of primary consolidation has been used for several large preloading applications where sand drains have been used to accelerate consolidation for one-story structures and for highway fills for high-speed roadways, but this is by no means a general figure and should 


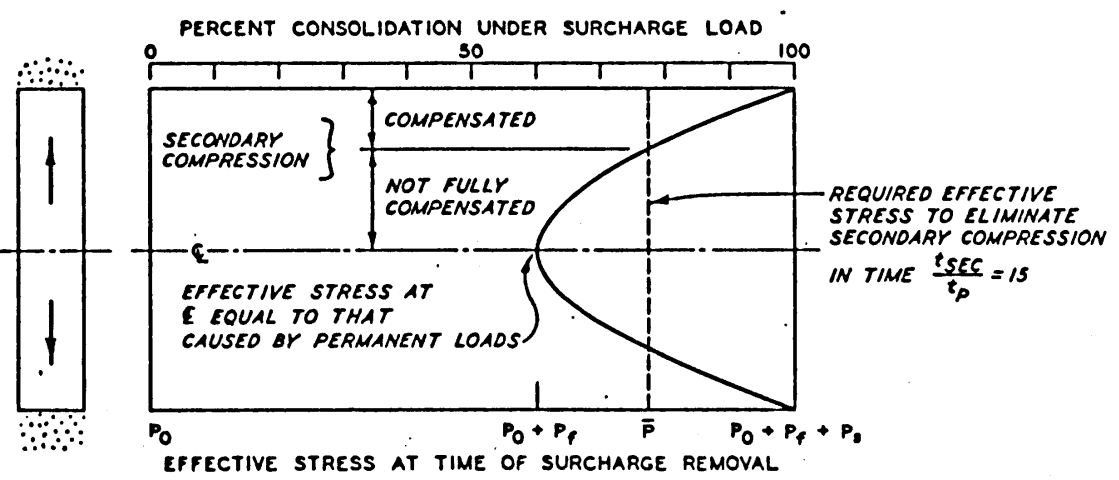

PARTIAL COMPENSATION OF SECONDARY COMPRESSION

54 
be arrived at according to the requirements of each job. Obviously, a building imposes more severe postconstruction settlement requirements than does a highway fill. However, modern highway fills intended for high-speed traffic require construction to high standards. When designing surcharge fills for buildings and high-speed roads, such as those of the interstate system, it is believed that at least one cycle of secondary compression should generally. be compensated for, and more if circumstances warrant.

Time Rate of Secondary Compression

The time rate of secondary compression remaining after completion of surcharge loading is so slow that generally it is not especially significant. Where it may be of interest, an approximation can be made from results of laboratory consolidation tests simulating field loading, but loadings in laboratory tests should be maintained for at least four to six weeks or longer. An alternative is to assume the validity of Taylor's diagram (Fig. 18). If this is done, the effect of surcharge loading is to change the settlement and time scales as shown in Figs. 20 and 22 , which is equivalent to saying that secondary compression after removal of surcharge load will proceed in accordance with:

$$
\Delta \mathrm{H}_{\text {sec }}=c_{\alpha} \cdot \mathrm{H}_{\mathrm{p}} \quad \log \cdot\left(I+\frac{\Delta t:}{t_{\mathrm{sc}}}\right)
$$

Where

$$
\begin{aligned}
\Delta \mathrm{H}_{\text {sec }}= & \begin{array}{l}
\text { secondary compression occurring after removal of } \\
\text { surcharge loading. }
\end{array} \\
\mathrm{H}_{\mathrm{p}}= & \begin{array}{l}
\text { total thickness of compressible stratum at completion } \\
\text { of primary consolidation }
\end{array} \\
\Delta t= & \text { time since removal of surcharge load }
\end{aligned}
$$

The benefits of surcharge loading to reduce postconstruction secondary compression are apparent in Fig. 22 and are more obvious if the time-settlement data are plotted.with arithmetic scales, as done in Fig. 23. It is evident that postconstruction secondary compression settlements can be reduced to small values. 


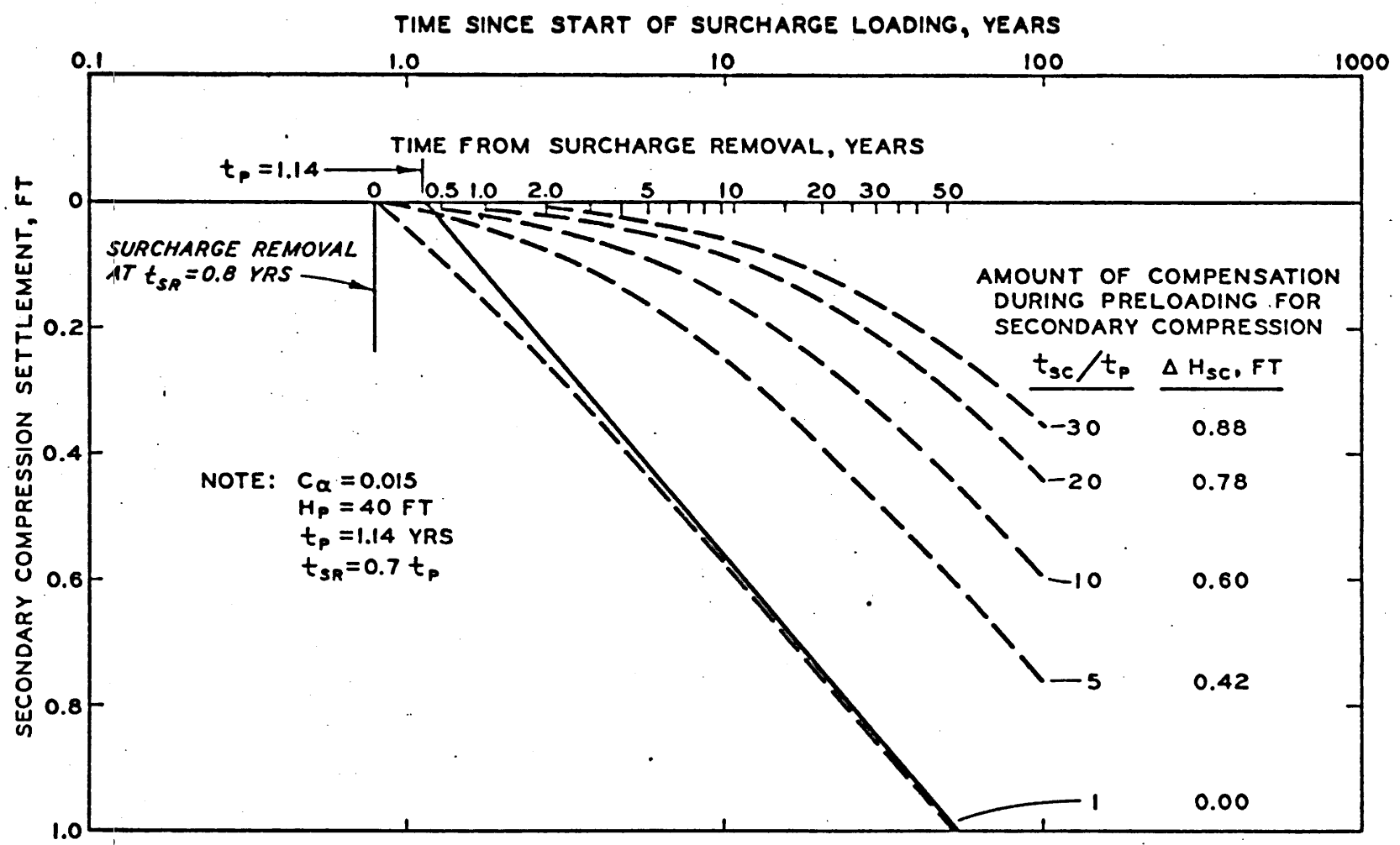




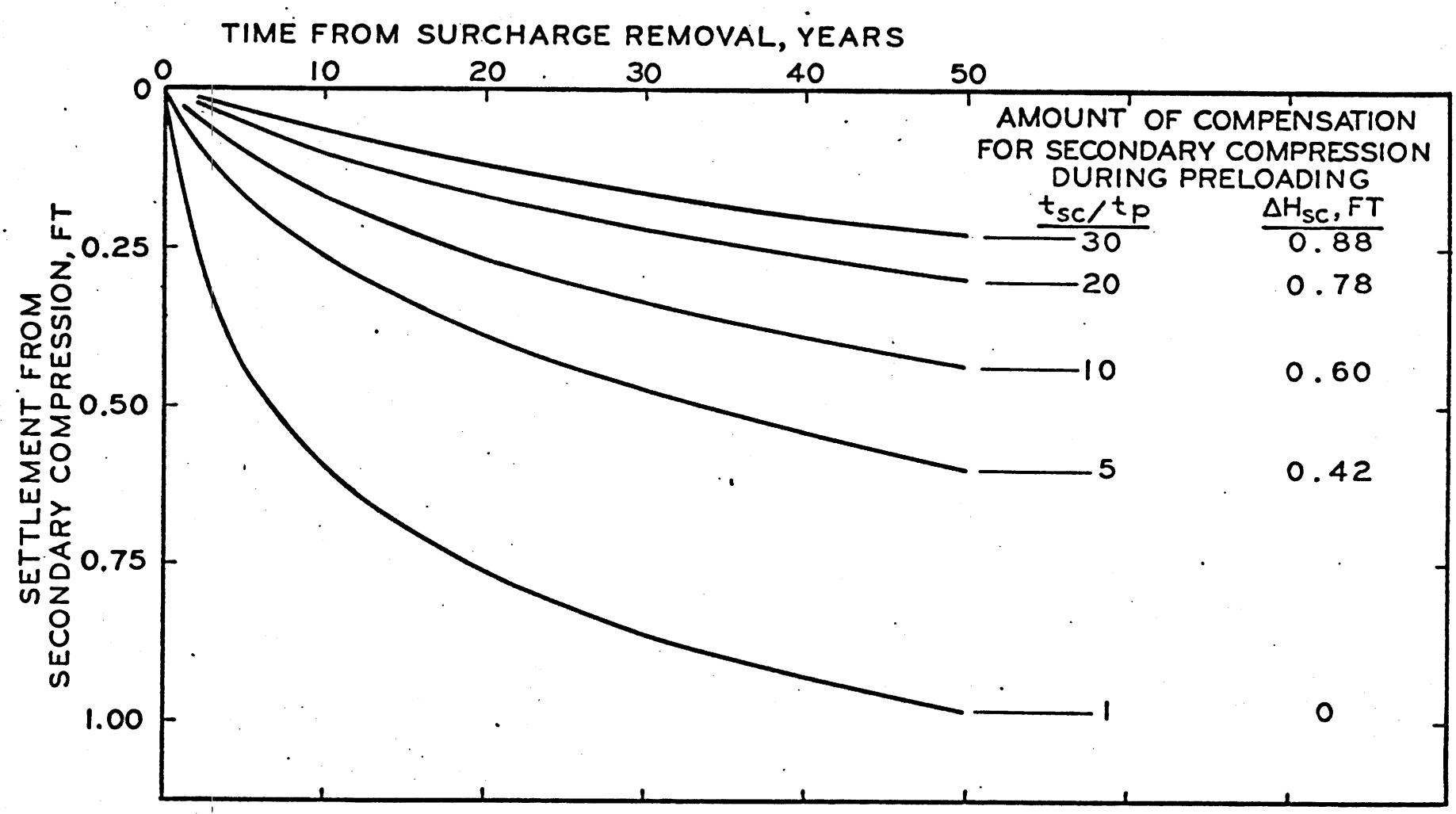
SETTLEMENTS AFTER REMOVAL OF SURCHARGE LOADING 
According to Eq. 12 and as may be seen in Fig. 22, the slope of the plot of settlement per unit thickness of compressible stratum versus log time will approach $c_{\alpha}$ for large time periods after removal of surcharge load. Thus, the effect of surcharge. loading on secondary compression is to displace the time plots so that $c_{\alpha}$ is reduced for small time intervals but not for large time intervals, after surcharge load removal. This does not imply that the total secondary compression of a structure will eventually be unaffected by temporary surcharge loading (see Fig. 23), since the parallel portions at large times are displaced laterally (see Figs. 22 and 23). The time plots shown in Fig. 22 may be compatible with effects of surcharge loading according to the limited laboratory test data illustrated schematically in Fig. 7. Unfortunately, laboratory tests have not been conducted for sufficiently long time periods to determine if time plots illustrated in Fig. 7 eventually develop into the type shown in Fig. 22, although a few tests indicate this is probable.

Consolidation of Partially

Saturated Soils

Many precompression applications involve organic soils that contain free gas or a zone of groundwater fluctuation that facilitates trapping gas. Any undisturbed sample recovered from below the groundwater level would probably be partially saturated because release of dissolved gas occurs as the sample is removed from the ground and the pore-water pressure is decreased. The use of back-pressure consolidometers ${ }^{51}$ permits the effect of in situ pore-water pressures to be simulated, thereby improving consolidation test results. However, even back pressures equal to in situ pore-water pressures may not cause all gas to be redissolved in some soils.

The application of load to a partially saturated soil causes immediate compression and rapid solution of gas until equilibrium under the new pore-water. pressure is achieved. The compression of free gas results in a volume decrease 
and an increase in intergranular stresses; in effect, it causes a rapid or immediate consolidation. However, after application of the load and compression of gas, consolidation results in decreased pore-water pressures, thereby permitting gas to come out of solution. This adds to the volume of free gas, which expands as pore-water pressures decrease. These effects cause the rate of consolidation following loading to be less than if the material is saturated, as shown in Fig. 24 taken from Reference 2. While effects of partial saturation on consolidation theory can be included, most practical applications do not require this provided that consolidation tests are used that simulate field loading conditions.

In a study of effects of partial saturation, Gould ${ }^{2}$ demonstrated the effect of various initial gas volumes and showed that even a relatively small amount of gas causes a large increase in immediate consolidation. However, subsequent consolidation proceeds much slower than if the soil did not contain gas, and its rate becomes progressively smaller for increasing degrees of consolidation. These effects must be considered when evaluating results from field instrumentation during early periods of surcharge loading: Consolidation theory for partially saturated soil is now in a stage of development. 2,43 


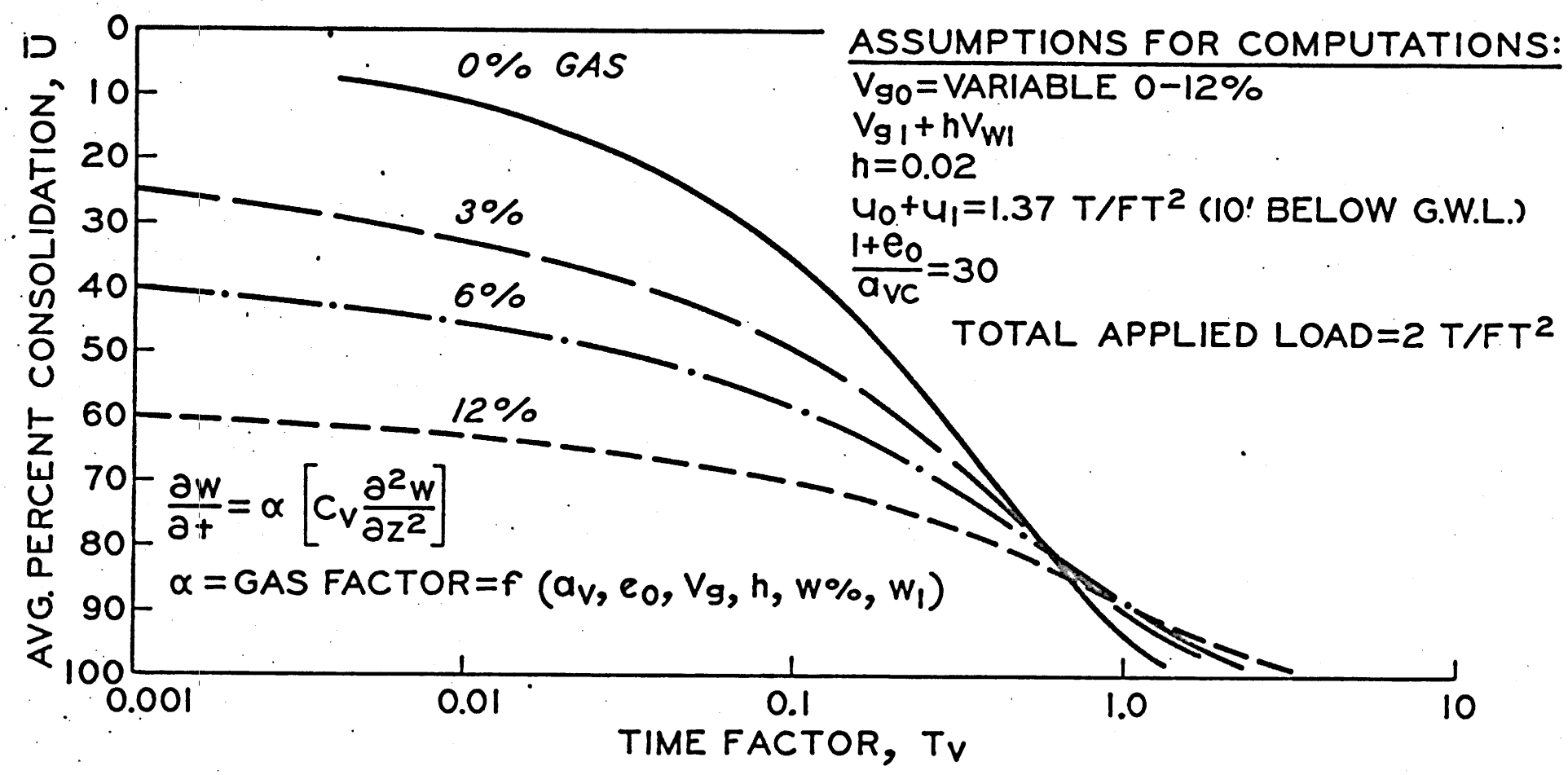

EFFECT OF GAS ON RATE OF CONSOLIDATION (PER GOULD-SAND DRAIN REPORT) . 


\section{GENERAI OBSERVATIONS ON FIEID PERFORMANCE}

Stability

While the theme of the conference excluded stability considerations, it seems necessary to at least mention stability during preloading because of the many instances where foundation instability has jeopardized or nullified precompression as a means for stabilizing poor subsoils. Providing foundation stability during preloading is especially difficult because of the need to do so at minimum expense for subsoils having low shear strengths, as is normally the case where precompression is used. Without going into details, extremely careful stability analyses must be performed to determine the stability of subsoils subjected to surcharge loadings. This one feature has and is still causing extreme difficulty in using the precompression technique, and yet it appears amenable to careful analysis and field supervision. Except under unusual circumstances, strength gain from consolidation during loading should not be relied upon to ensure foundation stability. Where a gain in strength from consolidation must be obtained to secure reasonable.construction costs, stage construction is recommended.

\section{Primary Consolidation}

From a practical standpoint, it appears well established that the magnitude of primary consolidation can be satisfactorily estimated from available consolidation theory. However, actual settlements are frequently somewhat greater than computed values. Time rates of primary consolidation also can be reasonably well estimated, but faster and slower rates are frequently. experienced. The decrease in the coefficient of consolidation with increasing effective stress, which has been well established in laboratory consolidation tests, definitely occurs under field conditions. This means that it is 
not possible to extrapolate directly the rate of consolidation experienced at one particular time interval to later time intervals when effective stresses are higher. Subsequent consolidation must be estimated considering the decrease in the coefficient of consolidation that occurs as consolidation proceeds.

Secondary Compression

It is considered that sufficient experience has been accumulated to conclude that settlements resulting from secondary compression can be estimated reasonably satisfactorily for practical purposes and can be minimized through proper use of surcharge loading despite many uncertainties regarding both magnitude and time rate of secondary compression. However, major advances in understanding of secondary compression are occurring and will almost certainly modify or supersede the interim design procedures suggested herein. 


\section{SOME EXAMPLES OF PRECOMPRESSION}

There are so many interesting examples of the use of precompression for. stabilizing poor subsoils beneath structures that the few selected for discussion cannot adequately portray the range of current applications. Those discussed involve precompression without use of sand drains or other means to accelerate consolidation. However, results where sand drains were used $2,23,47,52$ also illustrate the precompression technique and further confirm the validity of the concept that primary consolidation and a portion of secondary compression can be avoided in the postconstruction period by proper precompression design.

Morganza Floodway Control structure ${ }^{3}$

This pile-supported structure is located adjacent to the Mississippi River about 35 miles northwest of Baton Rouge, La. Subsoils consist of about $80 \mathrm{ft}$ of clay, with water contents generally between 42 to 60 percent and liquid limits between 60 and 100, overlying a thick stratum of sand. A preload fill was placed at the south abutment in October 1949 and at the north abutment in July 1950 in an effort to minimize drag and bending of piles supporting the structure and to avoid possible underseepage problems. The preload fill was extended over the wing wäl locations.

A photograph of the structure is shown in Fig. 25; a typical section showing the preload fill at the abutments is shown in Fig. 26; and settlement records and preload fill heights are shown in Fig. 27 . The $2-1 / 2$ ft of settlement that occurred during the preload period obviously greatly reduced postconstruction settlements beneath the structure. The latter were minor and could have been reduced even further if a higher surcharge fill had been used, but this was not common practice at the time this work was designed. This is one of the earliest known uses of precompression at a major hydraulic structure. 


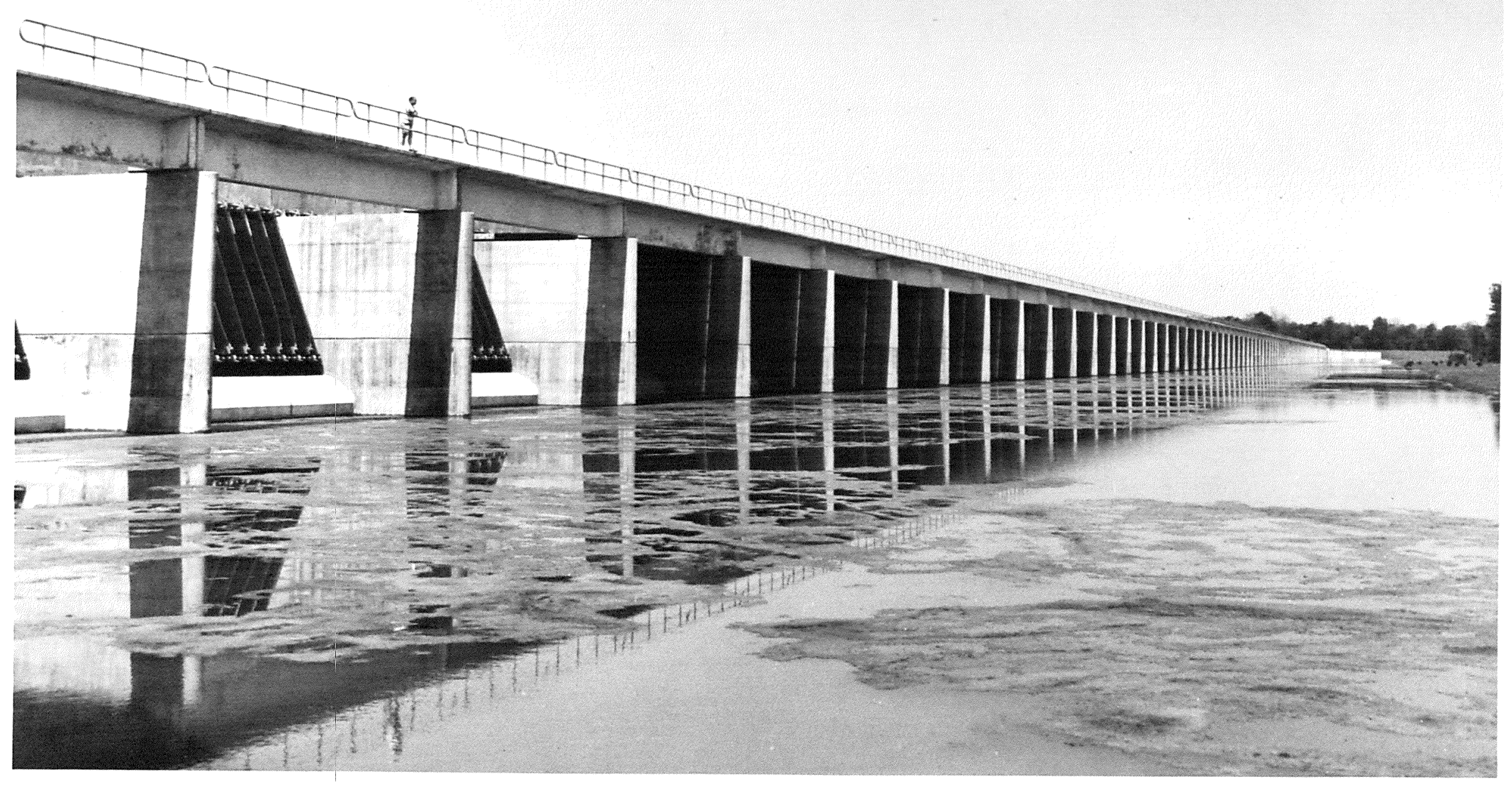




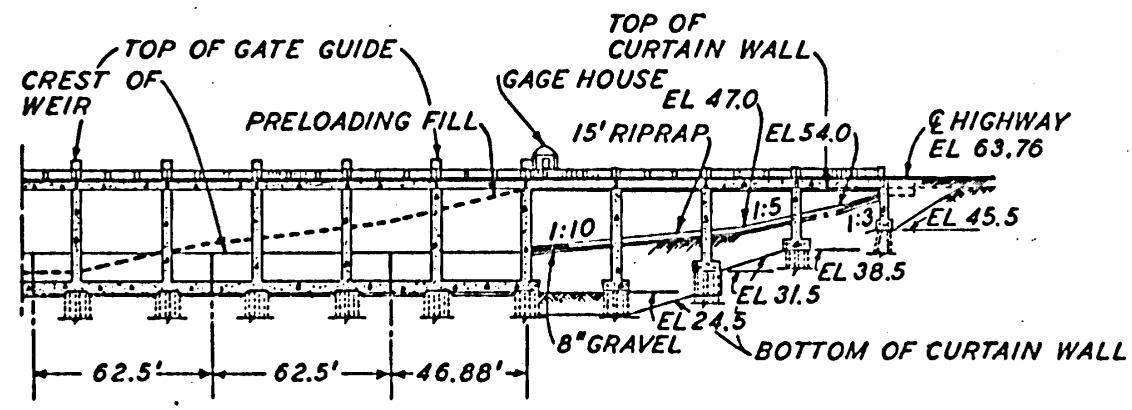

ABUTMENT PRELOOAD FILLS

MORGANZA FLOODWAY CONTROL STRUCTURE 


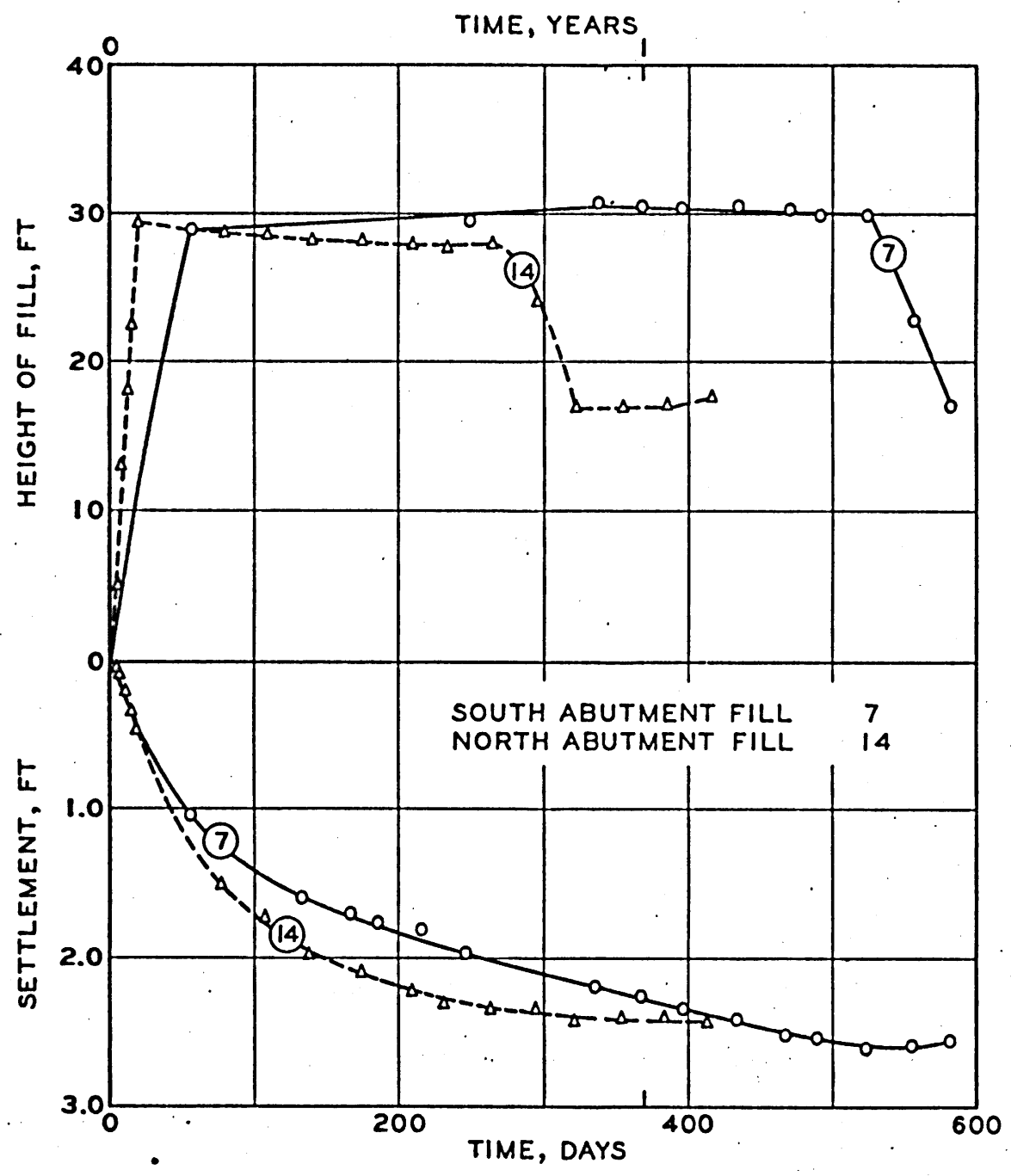

SETTLEMENT OF PRELOAD FILLS AT ABUTMENTS MORGANZA FLOODWAY CONTROL STRUCTURE 
Old River Low-Sill Control Structure ${ }^{5}$

This pile-supported structure (see Fig. 28) is located on the west bank of the Mississippi River about 35 miles south of Natchez, Miss.; it controls normal low-water flow from the Mississippi River into the Atchafalaya River. Because subsoils consist of compressible silts and clays, preload fills were used at the abutments to reduce large postconstruction settlements that would have otherwise occurred. Precompression was used to avoid a downward drag on piles near the abutments and to avoid possible pulling away of earth fill at seepage cutoffs. The clays had water contents of about 35 to 50 percent, Iiquid limits from about 50 to 90 , and plasticity indexes of 30 to 60 . Below a depth of about $30 \mathrm{ft}$, the subsoils were principally silt and silty sand. A section at the abutment is shown in Fig. 29, and results of settlement observations at the south abutment are shown in Fig. 30. It is evident that the preload fills accomplished their intended purposes. The rate of settlement was much faster than anticipated, evidently because of silt and sand layers in the compressible materials. Total settlements were about $1.9 \mathrm{ft}$ more than anticipated, largely because the compressibility of the silts and silty sands, especially between depths of 30 to $70 \mathrm{ft}$, was underestimated. While this had no practical significance because of preloading, it demonstrates the special value of precompression at structures. The large settlements that would otherwise have occurred would have been difficult to accommodate.- Theseresults also demonstrate the difficulty of obtaining close agreement between expected and actual settlements. Old River Overbank Control Structure.

This structure controls overbank flood flows from the Mississippi River to the Atchafalaya River and is located on the west bank of the Mississippi River about 35 miles south of Natchez, Miss. The structure (see Fig. 3I) is 


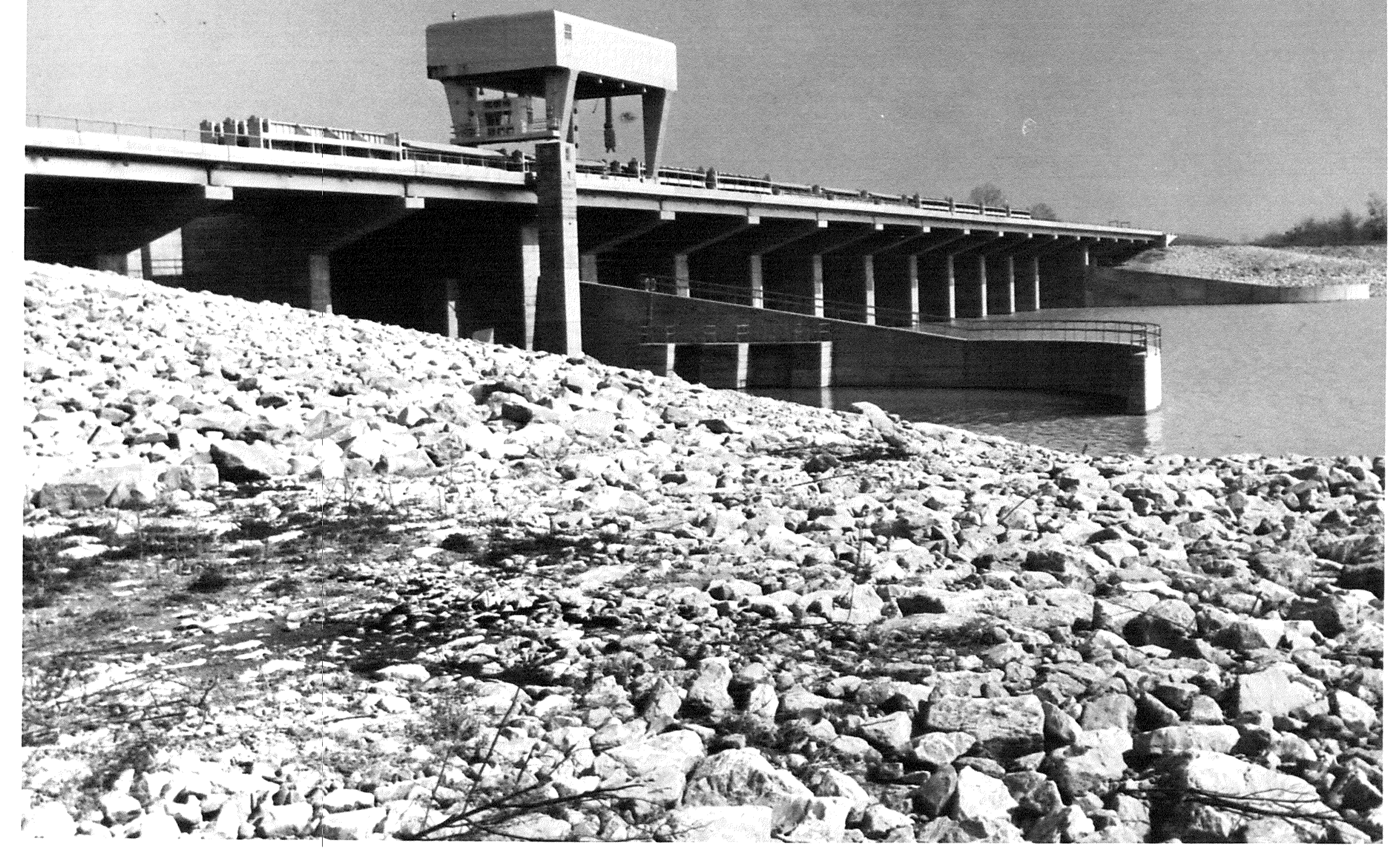




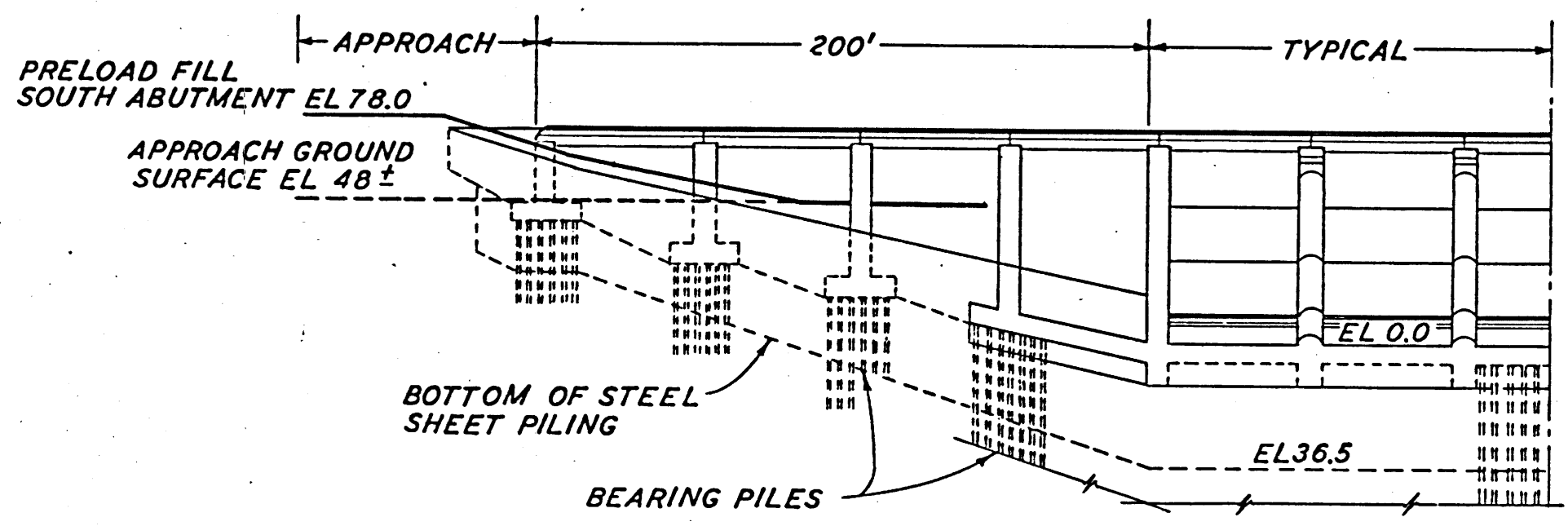

PRELOAD FILL AT ABUTMENTS

OLD RIVER LOW-SILL CONTROL STRUCTURE 


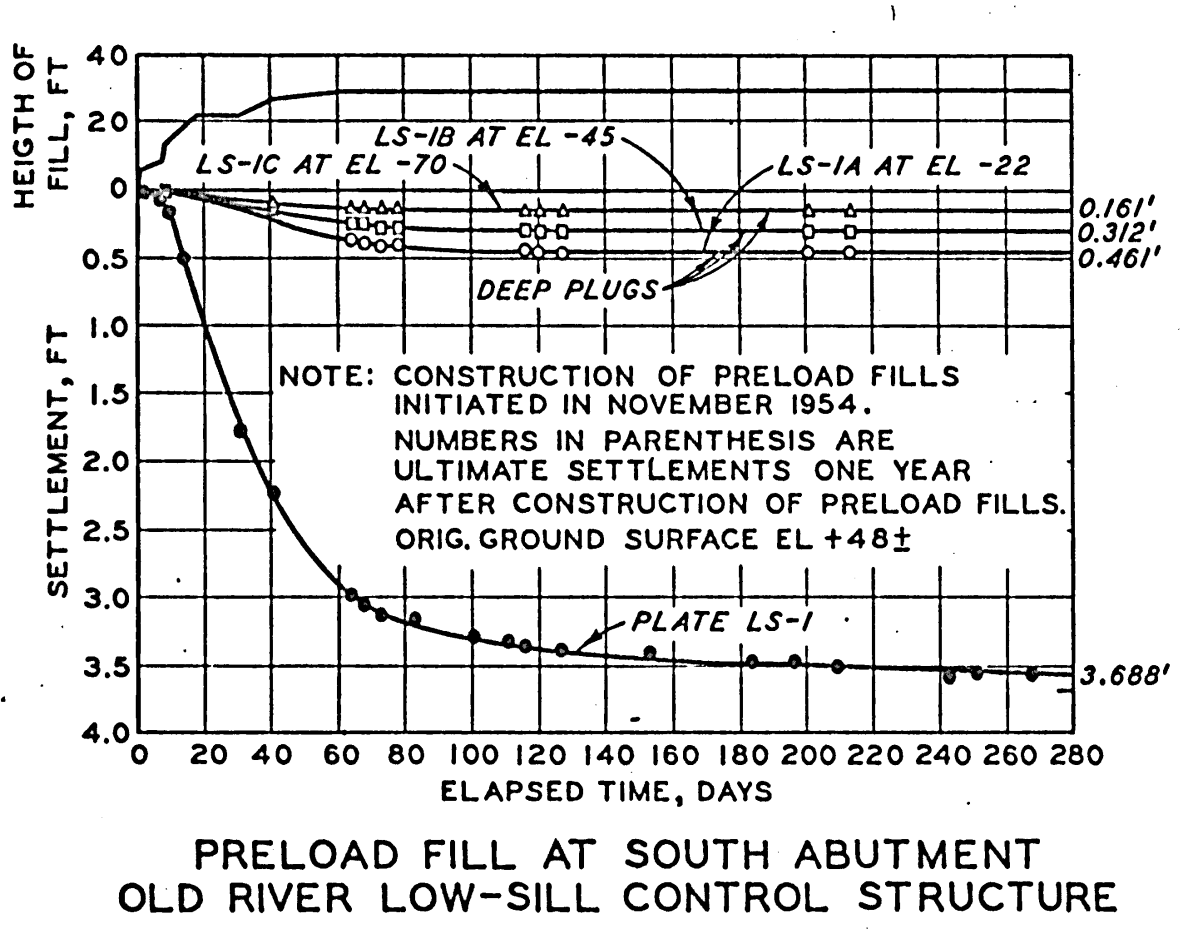




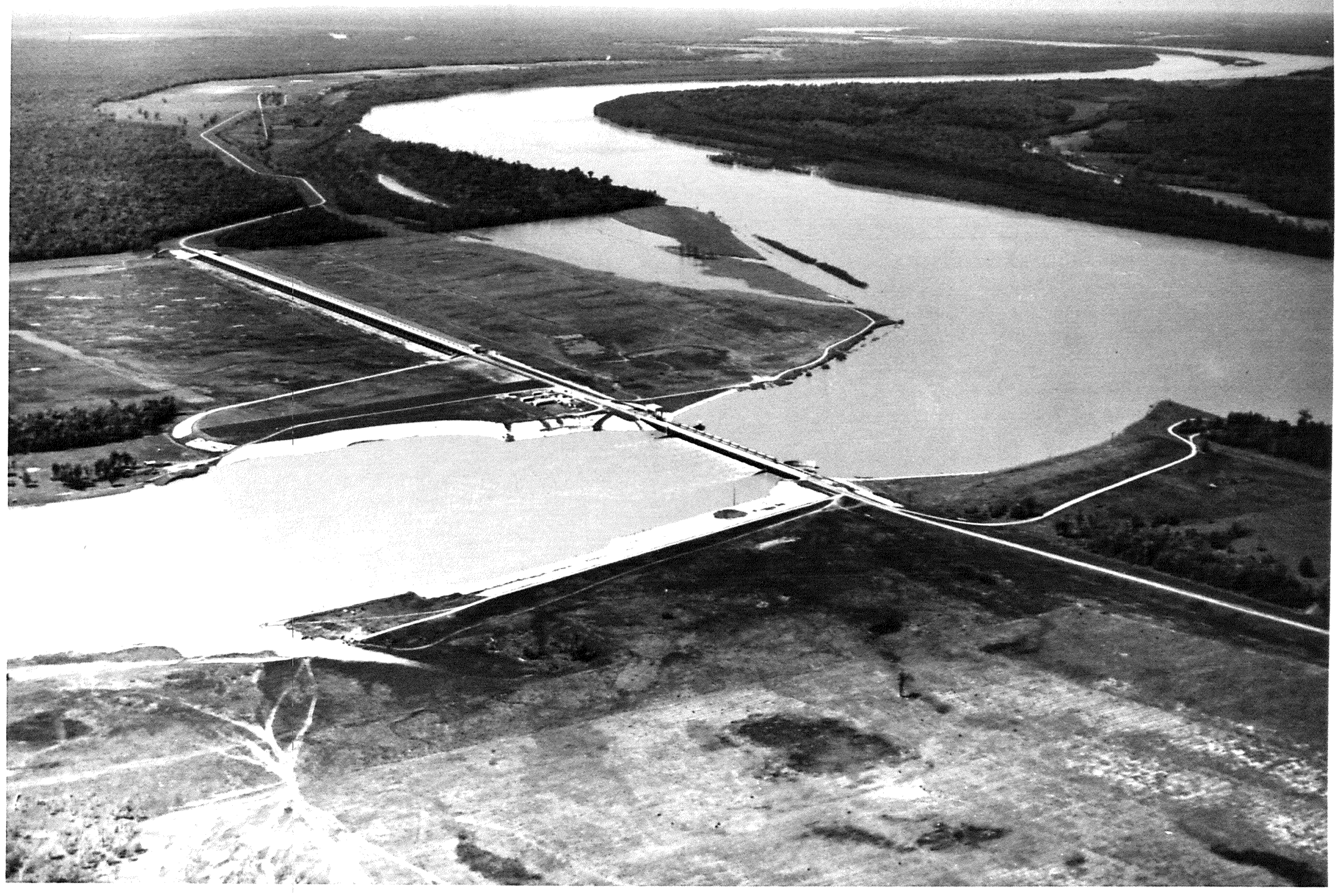


$3356 \mathrm{ft}$ long and is supported directly on about 25 to $30 \mathrm{ft}$ of clays overlying about $15 \mathrm{ft}$ of silt, sandy silt, and silty sands. The clays have water contents varying from 30 to 50 percent, averaging 42 percent, and liquid limits between 50 and 100 .

Because 24-ft-high earth fills at the abutments would cause larger stresses in the foundation than those caused by the structure, substantial total and differential settlements in the abutment areas could result. These were avoided by using preload fills, including 8-ft-high surcharge portions, at 'each abutment (see Fig. 32). The settlements caused by the preload fills after 12 months are shown in Fig. 32, and time settlement records are shown in Fig. 33. These indicate the important advantages of precompressing the foundation prior to construction of the structure. Total postconstruction settlements in the abutment areas were about 0.1 to $0.2 \mathrm{ft}$, with no sharp differential settlements. The total settlement during the preloading period was about 35 percent more than expected and occurred more rapidly than anticipated. The unexpectediy sharp variation in settlement of plates 2 and 3 at the south abutment may have resulted from displacement of the settlement plates as fill was placed or may illustrate the benefits of precompression as a means for avoiding sharp differential settlements in the structure that might otherwise occur because of undetected variations in the subsoil profile. Port Elizabeth Marine Terminal (Buildings 131 and 132 ) 18

Kapp, et $a l^{26}$ have summarized several precompression applications at the Port of New York Marine Terminals at Port Newark and at Port Elizabeth, located in the Jersey Meadows just west of New York City. Structures and floors of storage sheds are now supported on precompressed subsoils, which avoids possible differential settlements between floors and column footings that sometimes occurred when the structures were pile supported. Subsoil conditions 

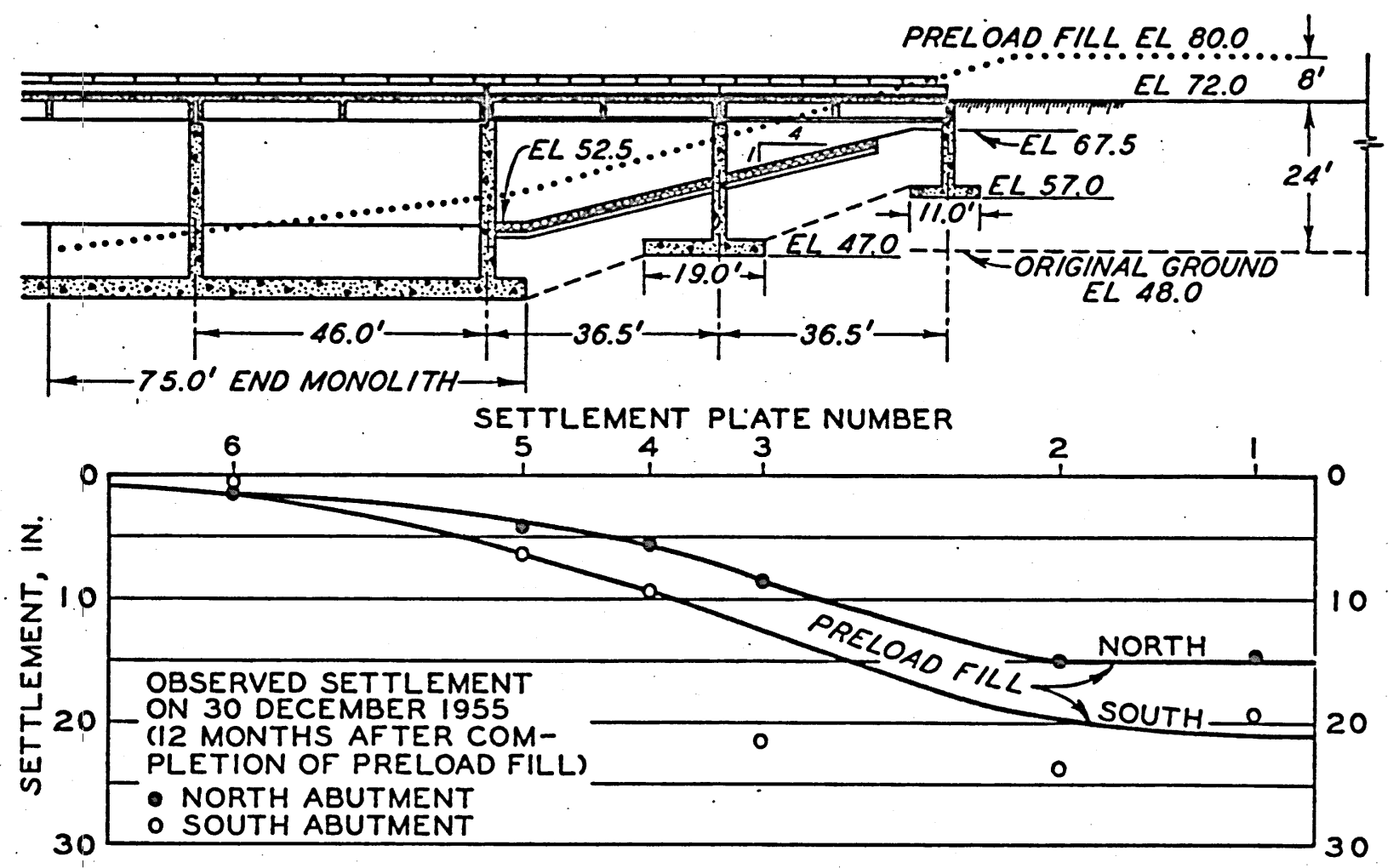

SETTLEMENT. PROFILES AT ABUTMENTS OLD RIVER OVERBANK CONTROL STRUCTURE 

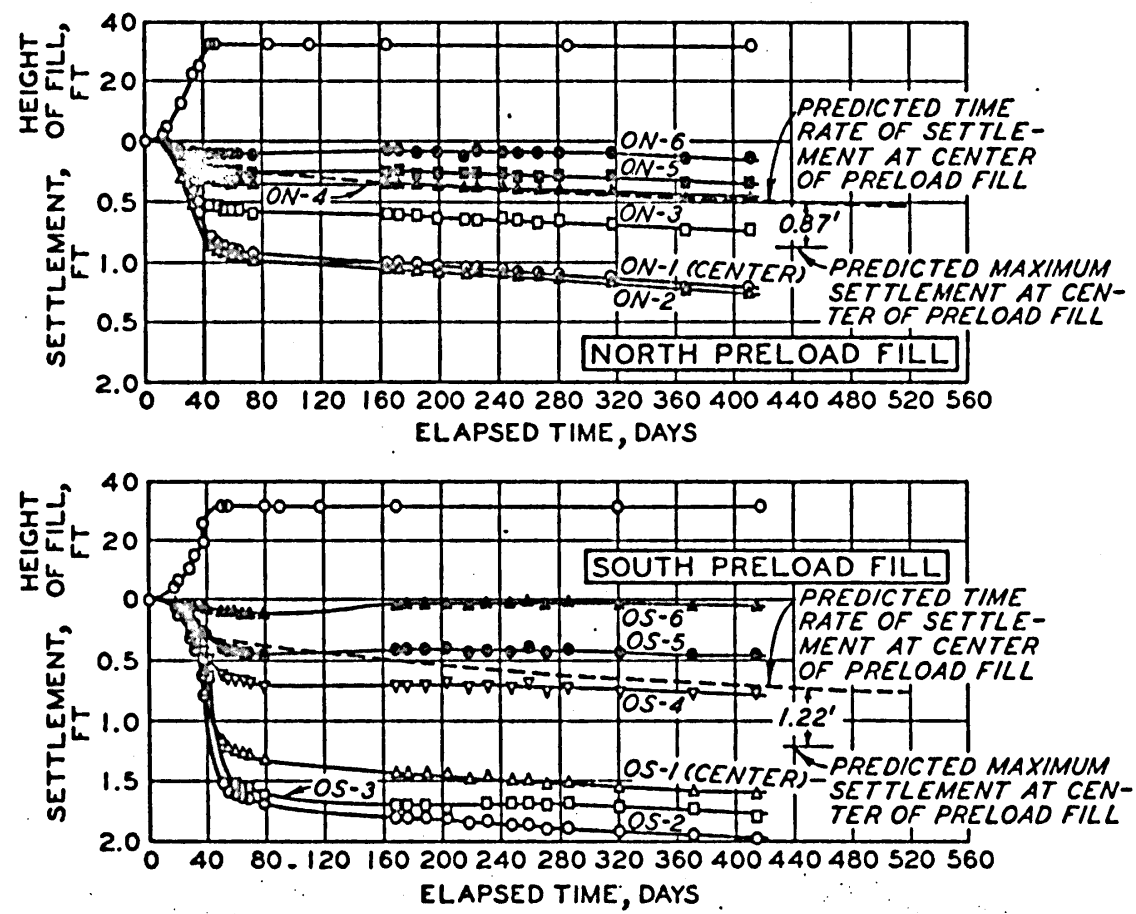

NOTE: ALL CURVES ARE OBSERVED SETTLEMENT EXCEPT AS OTHERWISE NOTED.

CONSTRUCTION OF PRELOAD

FILL AT NORTH ABUTMENT

INITIATED ON IS NOV. 1954.

CONSTRUCTION OF PRELOAD

FILL AT SOUTH ABUTMENT

INITIATED ON 10 NOV. 1954.

OBSERVED SETTLEMENT BENEATH PRELOAD FILLS OLD RIVER OVERBANK CONTROL STRUCTURE 
at one preload fill area are shown in Fig. 34, and settlement time observations are shown in Fig. 35. The average settlement was somewhat more than estimated and the maximum was about $1.3 \mathrm{ft}$ larger. This illustrates the variability in results that can sometimes occur. Postconstruction settlements correspond to a coefficient of secondary compression of 0.109 , which is about four times the laboratory determined value of 0.028 . However, the authors state that complete primary consolidation may not have been obtained throughout the stratum of peat and peaty organic silt. This explanation appears probable, since piezometers indicated slow pore-pressure dissipation. Postconstruction settlements of 0.2 to 0.4 ft were uniform and caused no structural problems or noticeable floor unevenness. 


\begin{tabular}{|c|c|c|c|}
\hline EL FT & W.L. & SOIL TYPES. & PROPERTIES \\
\hline 306.0 & & $\begin{array}{l}\text { LOOSE } \\
\text { MED. TO FINE } \\
\text { SAND FILL }\end{array}$ & $\begin{array}{l}\gamma=110 \text { P.C.F. } \\
\gamma^{\prime}=65\end{array}$ \\
\hline $\begin{array}{r}301.5 \\
5.5^{\prime}\end{array}$ & & $\begin{array}{l}\text { VERY SOFT } \\
\text { REDDISH BROWN } \\
\text { CLAYEY SILT } \\
\text { FILL }\end{array}$ & $\begin{array}{l}\gamma^{\prime}=50 \\
W-M I N .=32 \% \\
M A X .46 \text { AVG }=38 \\
\delta_{c}=0.10 C_{V}=0.12\end{array}$ \\
\hline 296.0 & $7=$ & $\begin{array}{l}\text { VERY SOFT } \\
\text { GREY ORGANIC } \\
\text { AND PEATY } \\
\text { ORGANIC SILTS } \\
\text { AND PEATS }\end{array}$ & $\begin{array}{l}\gamma^{\prime}=13 \text { P.C.F. } \\
W-M I N .=79 \% \\
W-M A X=569 \\
W-A V G .232 \\
C_{C}=2.52 \\
C_{V}=0: 15 F^{2} / D A Y \\
C_{\propto}(L A B)=0.028\end{array}$ \\
\hline 286.0 & o & $\begin{array}{l}\text { MED. COMPACT } \\
\text { F-VF. GREY SANDS } \\
\text { AND SILTY SAND }\end{array}$ & - \\
\hline
\end{tabular}

TYPICAL BORING

PORT ELIZABETH MARINE TERMINAL BUILDINGS I3। AND 132 


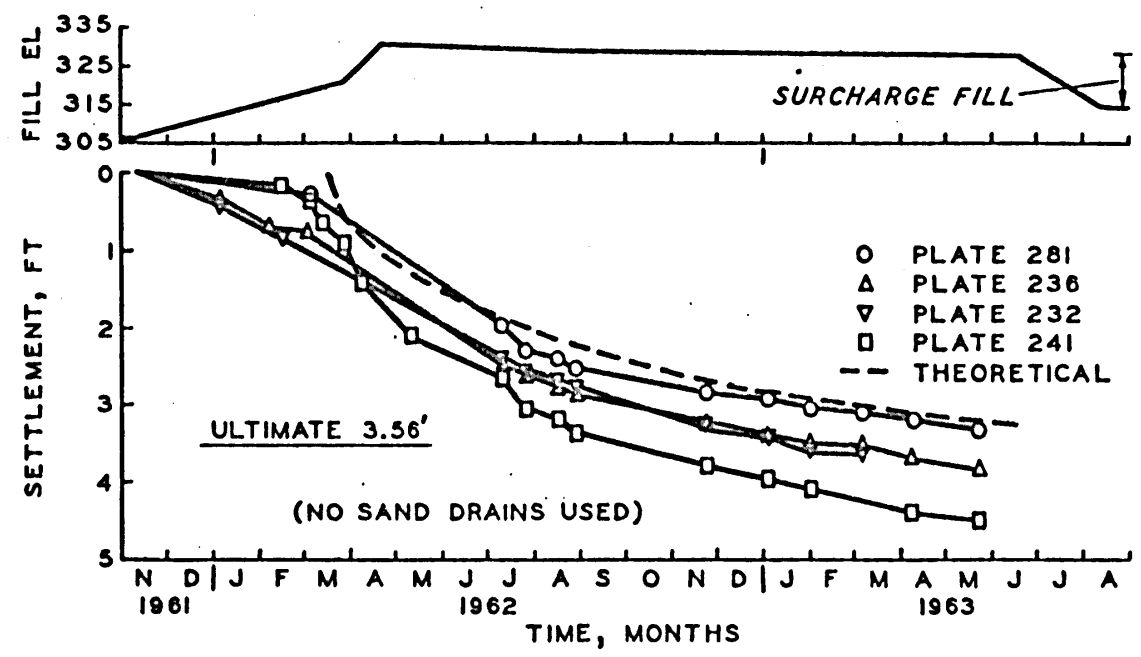

PRECOMPRESSION FOR SUPPORT OF WAREHOUSES PORT OF NEW YORK: AUTHORITY - BLDGS.I3I AND 132 (KAPP ET AL) 
Factors have been discussed that a design engineer evaluates when considering precompression techniques; but nothing has been said concerning if or how a safety factor is to be introduced into precompression design. When analyses are made for foundation stability during preloading, it is common to require a minimum safety factor, such as 1.25 or more. However, in making precompression designs for stabilizing poor subsoils, most engineers do not seem to introduce safety factors in either their total or time rate of settlement estimates, despite possible annoying or serious consequences of relatively minor deviations from predicted results.

It is difficult to compute precisely the magnitude of settlement that will result when few borings are made and these are distributed over large areas. Yet, if the soil is more compressible in some areas than assumed, the surcharge fill provided may be inadequate to precompress the soil to the desired degree. While this, of course, is a compelling reason for using instrumentation, even liberal use of instrumentation may be inadequate. Furthermore, estimating the time rate of consolidation involves numerous uncertainties; and a high degree of precision cannot be expected; nevertheless, this is a major element of precompression. design. The engineer could make technically sound predictions of time rate and magnitude of settlement that could still be sufficiently in error to inconvenience seriously constmation of a structure or paving of a roadway. Consequently, design studies should determine the range of results that can reasonably be expected, and the owner informed accordingly. Construction supervision must be regarded as an extension of the design phase, and the designer must be prepared to modify the design plans to conform to actual field conditions. This can be done fairly readily only if anticipated when preparing the plans and specification. 
It would be convenient to suggest specific safety factors to be applied to both magnitude and time rate of settlement computations; while this could perhaps be done, it would have meaning only for the person suggesting them. Only the designer himself is fully aware of the conservativeness of assumptions (1) made in evaluating boring and testing information, (2) involved in theories used and their applicability to actual subsoil conditions, and (3) applied. when using available design procedures. The present general practice of arriving at estimates of magnitude and time rate of settlement using "design" values for soil properties which involve no significant margin for unforeseen conditions is probably satisfactory, provided that the engineer and the owner anticipate the possible need for modifying the design during construction or during the preloading period. If this becomes necessary, it does not necessarily imply that the original design was unsuitable or poorly conceived. However, where either the owner or the engineer is unwilling to accept design modifications during construction, a safety factor should be applied to estimates for both magnitude and time rate of settlement. While the appropriate safety factor is a subjective matter that depends upon site conditions, experience available, and extent of subsoil exploration and testing, both magnitude and time required for preloading could easily. exceed normal design estimates by 25 percent or more. 


\section{CONCLUSIONS}

The precompression technique is a highly effective and economical means for improving subsoils beneath structures and embankments. However, it often requires considerable time, from months to a year or more, and its possible use must be anticipated during planning stages of a project. Precompression is not well suited where local concentrated loadings are high.

Precompression is an effective means for eliminating, in advance of construction of structures or roads, primary consolidation and a portion of secondary compression that would otherwise occur. The amount of secondary compression that is avoided by precompression can be estimated reasonably well, and the surcharge fill designed to reduce remaining secondary compression settlements to tolerable amounts.

Observations and confirmation of design assumptions during construction should be regarded as an essential extension of the design phase.

The combined problems of stability, settlement magnitude, and time rate, and of postconstruction settlements from secondary compression make precompression design about as demanding as any problem normally encountered in foundation engineering. The uncertainities involved and judgments required imply that the design process is in part an "art." While this is perhaps true and experience in this work is most valuable, it is also believed that serious pitfalls will be avoided by thorough investigations, designs, and construction supervision. 
1. Aldrich, H. P., "Precompression for Support of Shallow Foundations," Journal of the Soil Mechanics and Foundations Division, ASCE, Vol. 9l, No. SM2, March, 1965 (see also Proceedings, ASCE Conference on Design of Foundations for Control of Settlement, Northwestern University, 16-19 June 1964).

2. Moran, Proctor, Mueser, and Rutledge, "Study of Deep Soil Stabilization by Vertical Sand Drains," report to Bureau of Yards and Docks, Department of the Navy, June, 1958, p. II-113 ff. (Reprinted by Office of Technical Services, Department of Commerce.).

3. U. S. Army Engineer Waterways Experiment Station, CE, "Review of Soils and Foundation Design and Field Observations, Morganza Floodway Control Structure," Technical Memorandum No. 3-384, Vicksburg, Miss., Aug., 1954.

4. U. S. Army Engineer Waterways Experiment Station, CE, "Review of Soils Design, Construction and Performance Observations, Overbank Structure, Old River. Control," Technical Report No. 3-642, Vicksburg, Miss., Feb., 1964.

5. U. S. Army Engineer Waterways Experiment Station, CE, "Review of Soils Design, Construction and Performance Observations, Low-Sill Structure, Old River Control," Technical Report No. 3-602, Vicksburg, Miss., June, 1962.

6. Wilson, S. D., "Control of Foundation Settlements by Preloading, "Journal of the Boston Society of Civil Engineers, Vol. XXXX, No. I, Jan., 1953 (see also "Contributions to Soil Mechanics, 1941-1953," Boston Society of Civil Engineers).

7. Sowers, G. F., "Foundation Problems in Sanitary Land Fills," Journal of the Sanitary Engineering Division, ASCE, Vol. 94, No. SAl, Feb., 1968. 
8. Brickell, R. G., and Smith, A. W., "The Treatment of Foundation Subsoils," New Zealand Engineering, October, 1959, pp. 323-337.

9. Polshin, D. E., and Tokar, R. A., "Maximum Allowable Non-Uniform Settlement of Structures," Proceedings, 4th International Conference on Soil Mechanics and Foundation Engineering, Vol. I, Paper 3a/31, 1957, p. 402.

10. Feld, J., Discussion, Paper $3 a / 31$ by D. E. Polshin and R. A. Tokar, Proceedings, 4th International Conference on Soil Mechanics and Foundation Engineering, Vol. III, 1957, p. 149.

11. Sowers, G. F., Discussion, Paper 3a/31 by D. E. Polshin and R. A. Tokar, Proceedings, 4th International Conference on Soil Mechanics and Foundation Engineering, Vol. III, 1957, p. 166.

12. Department of the Navy, Bureau of Yards and Docks, "Soil Mechanics. Foundations and Earth Structures," Design Manual Navdocks DM-7, p. 7-6-8.

13. Ohsaki, Y., "Settlement and Crack Observations of Structures," Soil and Foundation, Japanese Society of Soil Mechanics and Foundation Engineering, Vol. I, No. 1, April, 1960.'

14. McKinely, D., "Field Observation of Structures Damaged by Settlement," Journal of the Soil Mechanics and Foundation Division, ASCE, Vol. 90, No. SM5, Sept., 1964.

15. Feld, J., "Tolerance of Structures to Settlement," Journal of the Soil Mechanics and Foundation Division, ASCE, Vol. 9I, Nō. SM3, May, 1965. .

16. Darragh, R. D., "Controlled Water Tests to Preload Tank Foundations," Journal of the Soil Mechanics and Foundation Division, ASCE, Vol. 90, No. SM5, Sept., 1964 (see also "Design of'Foundations for Control of Settlement," Soil Mechanics and Foundation Division, ASCE).

17. Scott, R. F., "Oil Tank Sites Preloaded by Wellpoint System," The Engineering Journal, Canada, Aug., 1959, p. 79. 
18. Halton, G. R., Loughney, R. W., and Winter, E., "Vacuum Stabilization of Subsoil Beneath Runway Extension at Philadelphia International Airport," Proceedings, 6th International Conference on Soil Mechanics and Foundation Engineering, Vol. 2, 1965, p. 61.

19. Golder, H. Q., and Sanderson, A. B., "Bridge Foundation Preloaded to Eliminate Settlement," Civil Engineering, Oct. 1961, p. 62.

20. Kjellman, W., "Consolidation of Clay Soil by Means of Atmospheric Pressure," Proceedings, Conference on Soil Stabilization, Massachusetts Institute of Technology, June, 1952, p. 258.

21. Penman, A. O. M., and Watson, G. H., "The Improvement of a Tank Foundation by the Weight of Its Own Test Load," Proceedings, 6th International Conference on Soil Mechanics and Foundation Engineering, Vol. 2, 1965, p. 169.

22. York, D. I., "An Example of Changes in Ground Water Levels During Consolidation," presented at Annual Meeting of ASCE, New York, N. Y., Oct., 1967.

23. Parsons, J. D., "Stabilization and Preparation of Marginal Areas for Building Construction," presented before Metropolitan Section, ASCE, New York, Mar., 1968

24. Jonas, E., "Subsurface Stabilization of Organic Silty Clay by Precompression," Journal of the Soil Mechanics and Foundations Division, ASCE, Vol. 90, No. SM5, Sept., 1964.

25. Simons, N. E., "Consolidation Investigation on Undisturbed Fornebu Clay," Norwegian Geotechnical Institute, Oslo, Publication No. 62, 1965.

26. Kapp, M. S., et al, "Construction on Marshland Deposits: Treatment and Results," Highway Research Record, No. 133, Highway Research Board, 1966.

. 27. Taylor, D. W., "Research on Consolidation of Clays," Publication from the Department of Civil and Sanitary Engineering; Massachusetts Institute of Technology, Serial 82, Aug., 1942. 
28. Lea, N. D., and Brawner, C. O., "Highway Design and Construction over Peat Deposits in Lower British Columbia," Highway Research Record, No. 7, 1963.

29. MacFarlane, I. C., Discussion of reference No. 28, Highway Research Record, No. 7 .

30. Terzaghi, K., and Peck, R. B., Soil Mechanics in Engineering Practice, 2nd Edition, John Wiley \& Sons, New York, 1967; pp. 73 and 87.

31. U. S. Army Engineer Waterways Experiment Station, CE, "Engineering Properties of Fine-Grained Mississippi Valley Alluvial Soils-Meander Belt and Backswamp Deposits," Technical Report No. 3-604, Vicksburg, Miss., June, 1962.

32. Gray, H., "Simultaneous Consolidation of Contiguous Layers of Unlike.Compressible Soils," Transactions, ASCE, Vol. ilo, 1945.

33. Harr, M. E., Foundations of Theoretical Soil Mechanics, McGraw-Hill, New York, 1966 , p. 141.

34. Scott, R. F., Principles of Soil Mechanics, Addison-Wesley Publishing .Co., Reading, Mass., 1963.

35. Schiffman, R. I., "Consolidation of Soil Under Time-Dependent Loading and Varying Permeability," Proceedings, Highway Research Board, Vol. 37, 1958, p. 584 .

36. Abbott, M. B., "One-Dimensional Consolidation of Multilayered Soils," Geotechnique, England, Vol. 10, No. 4, Dec., 1960, p. 151.

37. Schiffman, R. I., and Gibson, R. E., "The Consolidation of Nonhomogeneous Clay Layers," Journal of the Soil Mechanics and Foundations Division, ASCE, Vol. 90, No. SM5, Sept., 1964.

. 38. Davis, E. H., and Raymond, G. P., "A Nonlinear Theory of Consolidation," Geotechnique, England, Vol. 15, No. 2, June, 1965, p. 161. 
39. Gibson, R. E., England, G. L., and Hussey, M. J. L., "The Theory of OneDimensional Consolidation of Saturated Clays. I. Finite Nonlinear Consolidation of Thin Homogeneous Layers," Geotechnique, England, Vol. 17, No. 3, Sept., 1967, p. 261.

40. Barden, L., "Primary and Secondary Consolidation of Clay and Peat," Geotechnique, England, Vol. 18, No. 1, March, 1968, p. 1.

41. deJong, G. deJ., "Consolidation Models Consisting of an Assembly of Viscous Elements or a Cavity Channel Network," Geotechnique, England, Vol. 18, No. 2, June, 1968, p. 195.

42. Yoshimi, Y., and Osterberg, J. O., "Compression of Partially Saturated Cohesive Soils," Journal of the Soil Mechanics and Foundations Division, ASCE, Vol. 89, NNo. SMlt, July, 1963.

43. Barden, I., "Consolidation of Compacted and Unsaturated Clays," Geotechnique, England, Vol. 15, No. 3, Sept., 1965, p. 267.

44. Rowe, Peter W., and Barden, Laing, "A New Consolidation Cell," Geotechnique, England, Vol. XVI, No. 2, June, 1966, p. 162.

45. Skempton, A. W., and Bjerrum, I., "A Contribution to the Settlement Analysis of Foundations on Clay," Geotechnique, England, Vol. 7, No. 4, Dec., 1957, p. 168.

46. Lambe, T. W., "Methods of Estimating Settlement," Journal of the Soil Mechanics and Foundations Division, ASCE, Vol. 90, No. SM5, Sept., 1964.

47. Johnson, S. J., "Foundation Precompression with Vertical Sand Drains," Session III, ASCE Specialty Conference on Placement and Improvement of Soils to Support Structures, Massachusetts Institute of Technology, Aug., 1968. (Submitted to ASCE for publication, spring, 1969.) 
48. Akai, K., and Adachi, T., "Study on the One-dimensional Consolidation and the Shear Strength Characteristics of Fully Saturated Clay, in Terms of Effective Stress," Proceedings, 6th International Conference on Soil Mechanics and Foundation Engineering, Vol. I, 1965, p. 146.

49. Bjerrum, I., "Seventh Rankine Lecture: Engineering Geology of NormallyConsolidated Marine Clays as Related to the Settlements of Buildings,." Geotechnique, England, Vol. 17, No. 2, June, 1967, p. 83.

50. Brooker, E. W., and Ireland, H. O., "Earth Pressures at Rest Related to Stress History," Canadian Geotechnical Journal, Vol. II, No. I, Feb., 1965.

51. Lowe, J. III, Zaccheo, P. F., and Feldman, H. S., "Consolidation Testing with Back Pressure," Journal of the Soil Mechanics and Foundations Division, ASCE, Vol. 90, No. SM5, Sept., 1964.

52. Schmidt, T. J., and Gould, J. P., "Consolidation Properties of an Organic Clay Determined from Field Observations," Highway Research Record, No. 243, Highway Research Board, Washington, D. C. 
The following symbols are used in this paper:

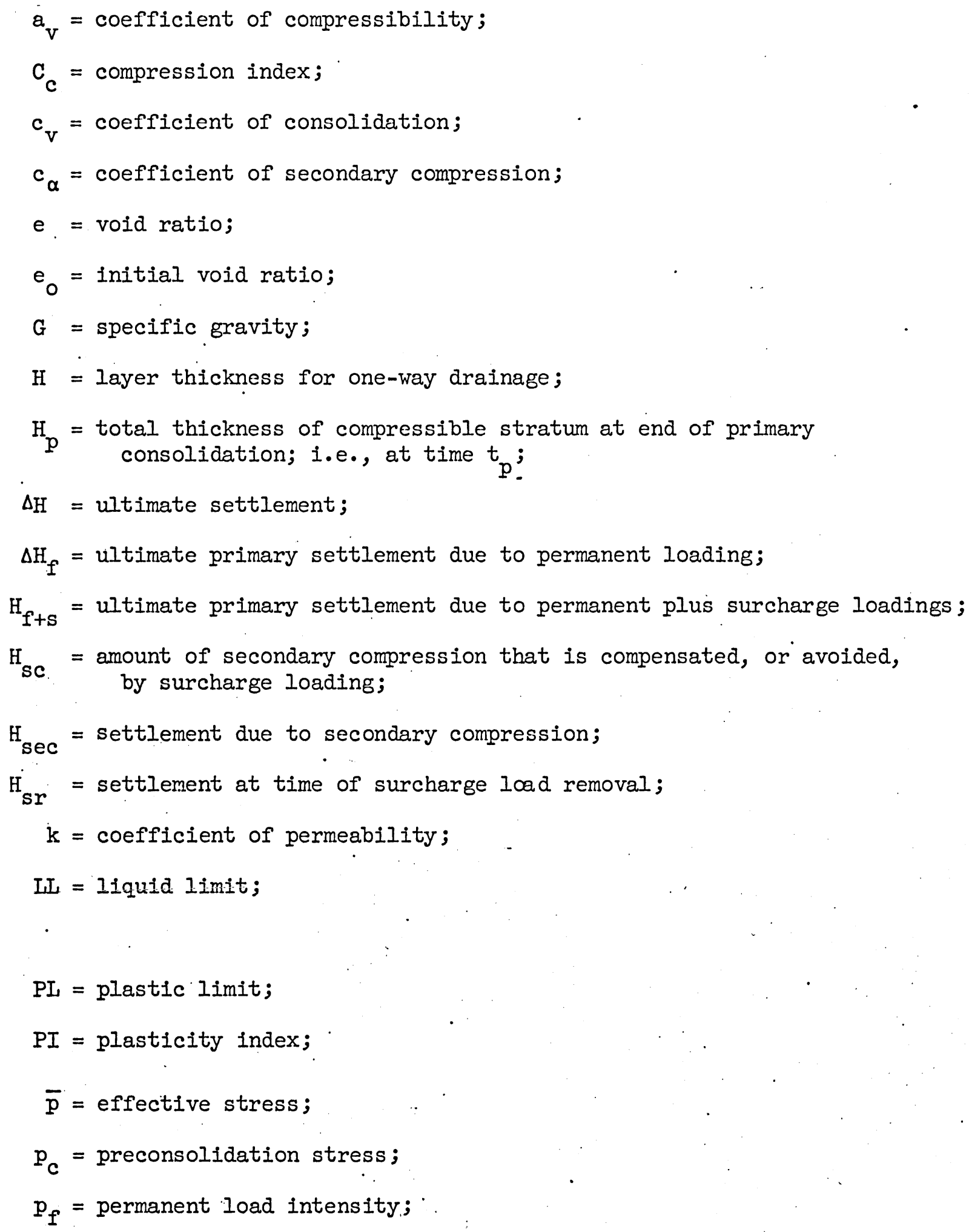




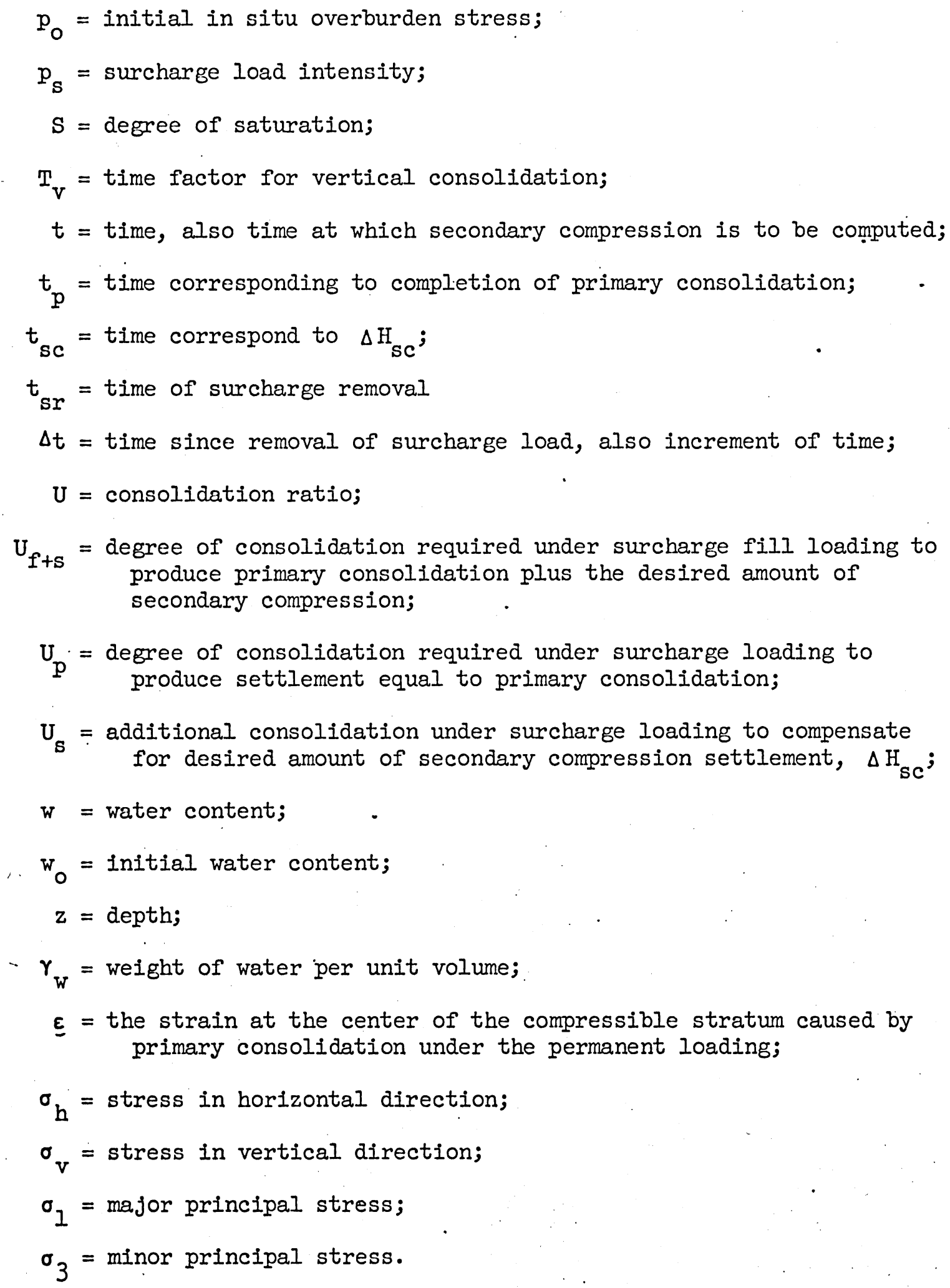
produce primary consolidation plus the desired amount of secondary compression;

$\mathrm{U}_{\mathrm{p}}=$ degree of consolidation required under surcharge loading to produce settlement equal to primary consolidation;

$\mathrm{U}_{\mathrm{s}}=$ additional consolidation under surcharge loading to compensate for desired amount of secondary compression settlement, $\Delta \mathrm{H}_{\mathrm{sc}}$; 
Influence of Structure Size Relative to Thickness of Compressible Soil

Effect of Preload-Induced Pore-Water Pressure on Stability

Consolidation Variables $\left(c_{v}, k\right.$, and $a_{v}$ ) for Tests on Good and Poor Undisturbed Samples

Laboratory Consolidation Curves for Poor Undisturbed Samples.

Laboratory Consolidation Curves for Good Undisturbed Samples

Coefficient of Secondary Compression c . (After Jonas) vs Effective Stress, One-Dimensional Consolidation

Effects of Stress Unloading on Secondary Compression-Laboratory Tests Secondary Compression-Variation of $\mathrm{C}_{\alpha}$ During Loading and Unloading Secondary Compression-Reduction in $c_{\alpha}$ vs Reduction in Stress

Effect of Stress Decrease on Secondary Compression-Laboratory Consolidation Tests (After Simons)

Effect of Stress Decrease on Secondary Compression-Iaboratory Consolidation Tests (After Kapp et al)

Coefficient of Secondary Compression vs Water Content and Void Ratio Preloading Design-Compensation for Primary Settlement by Temporary Surcharge Fill

Excess Pore-Water Pressure and Degree of Consolidation When Average Degree of Consolidation Is 50 Percent

Precompression to Eliminate Primary Consolidation

Consolidation by Vertical Drainage. Hydrostatic Excess Pressure as Function of Time Factor $\mathrm{T}_{\mathrm{v}}$ and Position $\dot{\mathrm{z}} / \mathrm{H}$

Secondary Compression. Isotropic and One-Dimensional Consolidation (After Akai and Adachi)

Surcharge Loading to Reduce Secondary Compression-Normally Consolidated Deposits (Based upon Taylor Concepts-1942)

Surcharge Ioading to Reduce Secondary Compression-Over-Consolidated Deposits

Partial Compensation for Secondary Compression by Temporary Surcharge Loading 
Partial Compensation of Secondary Compression

Effect of Surcharge Loading on Secondary Compression Settlements After Removal of Surcharge Loading (Time Plotted on Logarithmic Scale)

Effects of Surcharge Loading on Secondary Compression Settlements After Removal of Surcharge Loading (Time Plotted on Arithmetical Scale) Effect of Gas on Rate of Consolidation (Per Gould)

Official Photograph - U. S. Army Engineer District New Orleans

Abutment Preload Fills of Morganza Floodway Control Structure

Settlement of Preload Fills at Abutments of Morganza Floodway Control Structure

Official Photograph - U. S. Army Engineer District New Orleans

Preload Fill at Abutments of Old River Low-Sill Control structure

Preload Fill at South Abutment of Old River Low-Sill Control Structure Official Photograph - U. S. Army Engineer District New Orleans Settlement Profiles at Abutments of Old River Overbank Control Structure Observed Settlement Beneath Preload Fills of Old River Overbank Control Structure

Typical Boring - Port Elizabeth Marine Terminal Buildings 131 and 132 Buildings 131 and 132 (Kapp et al) 